\title{
A Review of Pediatric Obstructive Sleep Apnea and the Role of the Dentist
}

\author{
Jacy Stauffer, DMD¹, David M. Okuji, DDS, MBA, MS², Guy C. Lichty II, DDS ${ }^{1}$, Rakesh Bhattacharjee, MD³, Fadra Whyte, DMD², \\ Daniel Miller, DDS 1 , Juveria Hussain, DMD 1
}

\begin{abstract}
${ }^{1}$ San Diego Children's Dental Clinic / San Ysidro Health, San Diego, CA; ${ }^{2}$ NYU Langone Dental Medicine/Hansjörg Wyss Department of Plastic Surgery/NYU School of Medicine, Brooklyn, NY; ${ }^{3}$ University of California - San Diego, Department of Pediatrics, Division of Respiratory Medicine, La Jolla, CA
\end{abstract}

\begin{abstract}
Pediatric obstructive sleep apnea (POSA), considered most severe in the spectrum of sleep-disordered breathing (SDB), is highly prevalent and affects up to $1 \%$ to $4 \%$ of all children. Approximately 7 to 9 million children experience POSA, prompting the medical and dental communities to improve awareness for proper screening, diagnosis, and earlier treatment. According to the American Academy of Pediatric Dentistry (AAPD), signs of untreated POSA in school-aged children can include neurocognitive dysfunction such as aggressive behavior, symptoms that resemble attention deficit hyperactivity disorder, deteriorating school performance, bedwetting, developmental delay, and reduced quality of life. Various surgical and nonsurgical techniques are currently being used in the treatment of POSA. Although it often improves symptoms, adenotonsillectomy (AT), the first line of therapy, may not be entirely curative in children with POSA. Further, recurrence of POSA is frequent even after AT is performed. Although dentists play critical roles in both screening and referral of children with symptoms of POSA, the dentist's role has recently evolved to include participation through a multidisciplinary approach in the management of children in whom POSA has been diagnosed. In this review, the etiology, epidemiology, and treatment considerations of POSA will be summarized with special emphasis on the dental provider's role in identifying and treating POSA.
\end{abstract}

Keywords: obstructive sleep apnea; pediatric obstructive sleep apnea; Sleep Disordered Breathing; Oral Appliance Therapy; myofunctional therapy; Pediatric Dentist; Orthodontist; breastfeeding; obesity

Citation: Stauffer J, Okuji DM, Lichty II GC, Bhattacharjee R, Whyte F, Miller D, Hussain J. A review of pediatric obstructive sleep apnea and the role of the dentist. J Dent Sleep Med. 2018;5(4):111-130.

\section{INTRODUCTION}

In recent years, sleep-disordered breathing $(\mathrm{SDB})$ and pediatric obstructive sleep apnea (POSA) have received more public attention and are now at the forefront of significant medical concern and areas of research. Sleep disordered breathing refers to a spectrum of sleep-related breathing abnormalities that include snoring, upper airway resistance syndrome, obstructive hypopnea syndrome, and obstructive sleep apnea (OSA). ${ }^{1}$ Given the high prevalence of comorbidities including neurocognitive dysfunction, cardiovascular complications, and obesity, SDB in children is a timely public health concern. ${ }^{1}$

Initially, the same diagnostic parameters used to diagnose OSA in adults was applied to children. ${ }^{2}$ Concurrent with the improved recognition of POSA has come the realization that because of the robust neurological development throughout childhood, young children are particularly susceptible to the effect of SDB, and that symptoms and polysomnographic characteristics of OSA in childhood are substantially different when compared with those of adults. This has led to refinements in how pediatric SDB and POSA are evaluated. ${ }^{2,3}$

Polysomnography, or overnight sleep studies, remain the gold standard for the diagnosis of POSA. The apnea- hypopnea index $(\mathrm{AHI})$, or the number of apneas and hypopnea per hour of total sleep time, is used to define POSA. ${ }^{4}$ Apneas represent more than $90 \%$ cessation of airflow and hypopneas, representing a partial reduction of airflow that results in an arousal from sleep and/or an oxyhemoglobin desaturation. ${ }^{4}$ Typically, an AHI within the range of 1.5 to 5 events/hour is considered mild, an AHI within the range of 5 to 10 events/hour is considered moderate, and an AHI $>10$ events/hour of total sleep time is considered severe POSA. ${ }^{5,6}$

Symptoms of POSA include loud snoring 3 or more nights per week, episodes of breathing cessation witnessed by another person, abrupt awakening accompanied by shortness of breath, mouth breathing including symptoms of dry mouth or sore throat, difficulty staying asleep with multiple nocturnal awakenings, restlessness, sweating, waking up in the morning feeling unrefreshed, and finally, frequent morning headaches. ${ }^{2}$ Daytime consequences of SDB may affect neurobehavioral, cardiovascular, and/or inflammatory systems. ${ }^{7}$

Regarding neurobehavioral consequences of POSA, children often exhibit daytime symptoms such as hyperactivity, inattention, irritability, and loss of appetite, which may translate to growth disturbances and poor school achievement. ${ }^{3}$ A cross-sectional study by Halbower et al. 
shows that severe POSA has an effect on Intelligence Quotient and executive functioning in children aged 6 to 16 years. ${ }^{8}$ Signs of untreated sleep apnea in school-aged children include behaviors associated with learning disabilities, such as poor school performance due to misdiagnosed attention deficit hyperactivity disorder, aggressive behavior, developmental delay, bed-wetting, and even failure to thrive. ${ }^{2}$ Studies have noted other severe outcomes of undiagnosed/untreated POSA including brain damage, seizures, coma, and cardiac complications. ${ }^{2}$ Patients with POSA are also at a greater risk of experiencing respiratory complications, including respiratory arrest after receiving general anesthesia or sedation. ${ }^{9}$

Although the most common etiology of POSA remains adenotonsillar hypertrophy, in young children the surge in childhood obesity has been a significant increase in the prevalence of POSA in all children, including adolescents. Treatment often includes adenotonsillectomy (AT), the first line of therapy for POSA ${ }^{5}$, however, surgical therapy frequently falls short, particularly in obese children, as shown in a retrospective study by Bhattacharjee et al. ${ }^{10}$ Thus treatment often includes the use of positive airway pressure (PAP), weight loss in obese children, and additional treatment strategies including dental therapies.

It is imperative for dentists to familiarize themselves with screening for SDB and POSA and to properly refer patients to the appropriate medical professional. In addition, dentists have the opportunity to play a prominent role in multidisciplinary teams that routinely treat children with POSA after proper physician assessment and diagnosis.

\section{EPIDEMIOLOGY}

Approximately $12 \%$ to $15 \%$ of children are affected by SDB, with the highest prevalence in preschool-aged children between the ages of 3 and 5 years. ${ }^{11}$ In $2 \%$ of children and $2.5 \%$ to $6 \%$ of adolescents in whom POSA has been diagnosed, the condition typically appears between the ages of 2 to 7 years, and unlike in adults, both sexes are affected equally ${ }^{12-14}$, however, following puberty POSA tends to be predominant in males. ${ }^{15}$

Habitual snoring (snoring > 3 nights/week) is common, affecting $3 \%$ to $12 \%$ of children, however, prevalence rates of POSA are more difficult to define given the variable diagnostic methods and criteria used for definition. ${ }^{5}$ Several epidemiologic studies report wide prevalence rates ranging from $0.8 \%$ to $24 \%$, but most report a true prevalence of POSA between $1 \%$ to $5 \%$ of all children. ${ }^{5}$ Due to the lack of resources to adequately diagnose POSA, both POSA and SDB remain undiagnosed in a significant percentage of children. ${ }^{2}$ Because children may present with less widely recognized signs and symptoms when compared to adults with OSA, there is an overarching concern that OSA in many children remain undiagnosed. ${ }^{2}$

\section{PATHOPHYSIOLOGY}

\section{Medical Etiology}

In children, hypertrophy of the tonsils and adenoids are the most common risk factors for SDB in children, followed by obesity, and craniofacial characteristics including choanal atresia, micrognathia, narrow palatal arch, dolichofacial pattern, macroglossia, and retrognathia. ${ }^{2,7,16}$ Central to the paradigm of SDB is an abnormal collapsibility of the upper airway during sleep leading to altered breathing as well as disturbances during sleep. ${ }^{2}$ These disturbances include arousals from sleep, sleep fragmentation, and disturbances in normal homeostatic gas exchange. ${ }^{2}$ There is substantial evidence as shown by a prospective study by Gozal and a randomized controlled study by Garetz et al. that AT improves clinical symptoms. ${ }^{17,18}$ However, many children with adenotonsillar hypertrophy do not meet the diagnostic criteria for POSA. ${ }^{17,18}$ These observations would suggest that the etiology of POSA in children is multifactorial and includes an intricate interaction between hypertrophy of the tonsils, craniofacial limitations, and alterations in tonicity of the neuromuscular system. ${ }^{1}$ Children with craniofacial syndromes are even more at risk for airway obstruction due to abnormalities in their anatomy, whereas hypotonia is the main cause of obstruction in children with neuromuscular disease. ${ }^{1}$

In addition to the aforementioned risk factors of POSA, and of particular relevance given current demographic trends, obesity adds significantly to the risk of POSA. ${ }^{19,20}$ As obesity prevalence rates have increased recently, there has been a concomitant observed increase in POSA. ${ }^{21}$ For every increase in body mass index (BMI) by $1 \mathrm{~kg} / \mathrm{m}^{2}$, the risk of POSA increases by $12 \% .^{12}$ The pathophysiology of obesity related to POSA is multifactorial as narrowing of the upper airway may result from fatty deposition of upper airway structures, including deposits in the anterior neck that can lead to pharyngeal collapsibility. ${ }^{22,23}$ Obesity also mass loads the respiratory system secondary to adipose tissue around the thoracic and abdominal walls, reducing overall pulmonary volumes and diaphragm excursion, and leading to substantial reductions in pulmonary reserve, particularly during supine sleep. ${ }^{24}$ Further, the degree of adenotonsillar hypertrophy that is required to culminate in POSA is less in obese children as shown in a retrospective cohort study by Dayyat et al. ${ }^{25}$ Finally, and adding to the complexity, obesity and POSA share many similar complications, including proinflammatory signaling cascades such that although obesity can lead to POSA, POSA itself is a risk factor for obesity; and the concurrence of both conditions likely results in a magnification of shared comorbidities. ${ }^{26}$

Sleep disordered breathing occurs within a range from snoring to severe OSA. ${ }^{3,27}$ Studies indicate that $34 \%$ of all children snore, therefore, it is important to distinguish primary snoring from snoring associated with POSA. Primary 
snoring is a common finding in childhood, and is not associated with apnea, oxygen desaturation, or hypoventilation. ${ }^{28}$ It is interesting to note that snoring itself, even without hypoxia and periodic arousals, has been linked with daytime cognitive and behavioral consequences indistinguishable to those identified with marked abnormalities in nighttime breathing. ${ }^{7}$ Sleep disordered breathing exists along a continuum of severity with indistinct boundaries between each syndrome. It is often difficult to tell where normal ends and pathology begins, ${ }^{29}$ as noted in Figure 1.

Children who were premature infants have a higher risk of SDB during childhood because of the relationships between low muscle tone, craniofacial growth, and oral versus nasal breathing. ${ }^{7}$ The severity of hypotonia is typically related to the level of prematurity in the infant. ${ }^{7}$ It is common for premature infants in correlation with a younger gestational age to display high vaulted and narrow arched palates. $^{7}$

According to the International Classification of Sleep Disorders, three sleep disorders are associated with children: primary sleep apnea of infancy, congenital hypoventilation syndrome, and POSA. ${ }^{28}$ Dayyat et al. describes two distinct types of POSA: one associated with hypertrophy of lymphadenoid tissue (type I) and the other (type II) which is more predominantly associated with obesity and more mild upper airway hypertrophy of lymphadenoid tissue. ${ }^{30,31}$ Given the confounding influence of obesity, type II is much less responsive to upper airway surgery. ${ }^{31}$ Finally, a proposed POSA type III would involve POSA related specifically to craniofacial abnormalities (e.g., Apert and Crouzon syndromes, Pierre Robin sequence, Down syndrome, Hemifacial Microsomia). ${ }^{31}$

In fact, POSA is very common in children with Down syndrome. Several studies, including a retrospective chart review by Rosen, reported prevalence of POSA ranging from $31 \%$ to $63 \%$, as compared with $1 \%$ to $4 \%$ in the general pediatric population. ${ }^{32} \mathrm{Waldman}$ et al. reported a prevalence of SDB in $50 \%$ to $80 \%$ of children with Down syndrome. ${ }^{33}$ Macroglossia is also a very distinct feature in patients with Down syndrome. ${ }^{16}$ Genetic and environmental factors may cause size differences in the tongue, soft palate, lateral walls, and mandible. ${ }^{16}$ Systemic diseases including amyloidosis, hypothyroidism, acromegaly, and nutritional deficiencies may also contribute to a diagnosis of macroglossia. ${ }^{16}$

Metabolic disorders such as polysaccharidosis can result in respiratory tissue thickening. ${ }^{2}$ Edema of the upper airway in infants with gastroesophageal reflux also places infants at higher risk for POSA. ${ }^{2}$ Genetic conditions such as achondroplasia may play an important role in regulating the size and shape of the soft and hard tissue forms of the upper airway. ${ }^{16}$ For example, retrognathia has a strong genetic influence in patients with craniofacial disorders such as Treacher Collins syndrome, which also places patients at a higher risk of POSA. ${ }^{16}$

Certain diseases, including immune dysfunction,

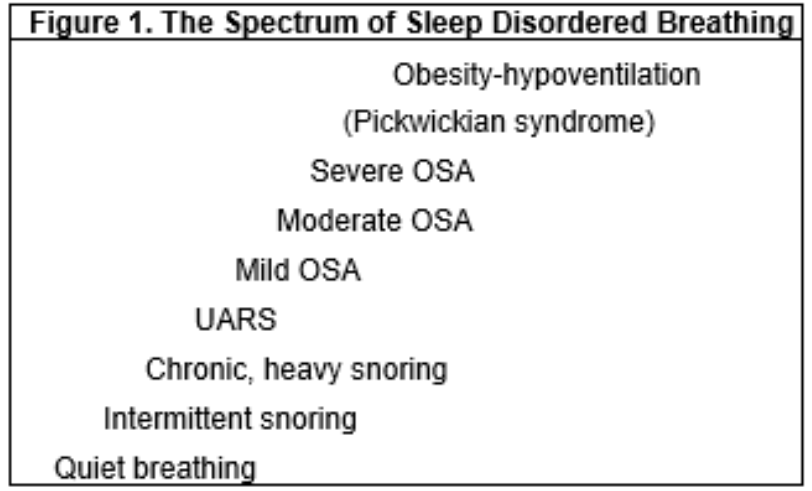

Lewis KL. Apneas, hypoapneas and respiratory effort-related arousals: moving closer to a standard. Curr Opin Pulm Med.2002;8(6):493-497. ${ }^{29}$

allergic rhinitis, chronic sinusitis, recurrent pharyngeal infections, and even malignancies could also be controlling the size of the tonsils, resulting in hypertrophy of the adenotonsillar area. ${ }^{16}$ Finally, local environmental irritants, ${ }^{27}$ such as exposure to environmental tobacco smoke, has also been associated with POSA. ${ }^{2}$

\section{Dental Etiology}

Since it is clear that the etiology of POSA is multifactorial, the net result likely involves changes in the compliance of the musculature of the upper airway, as well as total cross-sectional area of the upper airway. ${ }^{34}$ Obstruction of the upper airway during sleep could also be the result of malformations in the maxilla, mandible, and other facial structures. ${ }^{34}$ Patients with distinct craniofacial characteristics including a long, narrow face (dolichofacial pattern), high and narrow arched palate, and retrognathia have been noted in various studies using cephalometry and dental casts of patients with OSA. ${ }^{34}$

The craniofacial skeleton reaches $60 \%$ of its adult size by age 4 years and $90 \%$ of its adult size by age 12 years. ${ }^{35}$ As previously discussed, genetic and environmental factors affect the development of possible craniofacial anomalies. ${ }^{35}$ Patients of African American or Far Eastern European descent are at higher risk for SDB, supporting a genetic disposition. ${ }^{35} \mathrm{~A}$ possible explanation can be noted by cephalometric analysis. African Americans usually present with a steeper mandibular plane angle and more steep inclination of the anterior cranial base (which may contribute to a more dolichofacial skeletal pattern increasing the risk for mouth breathing). ${ }^{36}$ Also, because of the steeper mandibular plane angle and downward rotation of the mandible, it may increase the risk for a class III malocclusion. ${ }^{36}$

It is estimated in the literature that African American children are four to six times more prone to experience POSA in comparison with Caucasian children. ${ }^{12}$ In a prospective cross-sectional study by Rosen et al., the authors discuss how African American children often come from lower socioeconomic backgrounds and are more prone to 
untreated SDB, although the underlying etiology is still unclear. ${ }^{37}$ The infant who is born prematurely is exposed to multiple medical comorbidities, including chronic lung disease and/or neurological problems, that could increase the likelihood of SDB in late childhood. This current study suggests that obesity and prematurity may have more of an influence on SDB than race, and can be better researched to understand how race may affect POSA. ${ }^{37}$ Because obesity is not reliably distinguished in this particular population-based cohort study, prematurity and race may in fact have the greatest effect on the development of POSA than obesity. ${ }^{37}$

In a previous study by Redline et al., the authors suggested an earlier development of OSA in African Americans caused by a discrepancy between soft tissue and nasopharyngeal measurements in addition to increased adenotonsillar hypertrophy. ${ }^{38}$

Genetics can also provide insight into the risk for OSA in the African American population. In a cohort study by Bruxbaum et al., a recessive mode of inheritance based on outcomes of AHI was discovered after adjusting for age and BMI, and the genetic component was found to be independent of BMI. ${ }^{39}$

Overall, African Americans present with more severe OSA and nocturnal desaturation most likely due to differences in anatomical findings in the upper airway as well as pharyngeal neuromotor control. ${ }^{40,41}$ This is particularly noted in a study by Stepanski et al., in which the authors concluded that African-American children (referred to their sleep center) are more at risk for POSA and cardiovascular comorbidities, because they were found to experience more severe episodes of oxygen desaturation in comparison with Caucasians and Hispanics (with similar age and BMI $){ }^{40}$ However, all populations experienced similar severity of SDB. ${ }^{40}$ In addition, patients of African American descent are more likely to encounter recurring symptoms of SDB following an AT, ${ }^{42,43}$ and are more likely to experience complications surrounding this surgical procedure as noted in a prospective study by Thongyamet al. ${ }^{44}$

Finally, Weinstock et al. reviewed screening and baseline data from the randomized controlled multi-site Childhood Adenotonsillectomy Trial (CHAT) to assess health outcomes in children in whom mild to moderate POSA was diagnosed. ${ }^{41}$ This study looked at early treatment with an AT versus close monitoring with conservative care to evaluate demographic and health characteristics affiliated with the occurrence and severity of POSA in children with a history of snoring to be considered for AT. ${ }^{41}$ The study affirmed previous studies finding that race (African American) is the most convincing predictor in evaluating the severity of POSA, however, the relationship between POSA severity and African-American race could not be explained by socioeconomic status, obesity, asthma, or hay fever. ${ }^{41}$ In conclusion, more large population studies are needed to ascertain the genetic and racial components of POSA.

Mouth breathing, while not formally considered as part of the SDB continuum, and largely unstudied, is thought by many to be an early contributor to SDB. ${ }^{7}$ It has been reported to occur in $10 \%$ to $25 \%$ of children. ${ }^{7}$ Meyer, in 1868 , described a distinctive facial feature, the "adenoid facies," related to adenoidal hypertrophy, leading to nasal obstruction and culminating in the "long face syndrome;" or a "dolichofacial" pattern. ${ }^{7}$ Studies with primates have shown that increased nasal resistance coupled with chronic oral breathing can alter facial growth. ${ }^{7}$

Nasal breathing is considered the normal respiratory pattern. ${ }^{34}$ Chronic mouth breathing, a marker for orofacial muscle dysfunction, can evolve over time, but in the case of nasal obstruction, it typically results from various sources such as a deviated septum, allergic and chronic rhinitis, adenotonsillar hypertrophy, and hypertrophy of the turbinates, placing the child at risk for POSA. ${ }^{7,34}$ Hence, the overall facial development of the child is then altered, including a high arch palate, long and narrow face, increased overjet, anterior open bite, and class II malocclusion resulting in retrognathia, ${ }^{34}$ although these characteristics may not be seen in every patient. Overall, mouth breathing is congruent with retrognathia of the mandible, increased lower facial third height, inferior position of the hyoid, anterior-inferior positioning of the tongue, and a change in postural habits including hyperextension of the head. . $^{34,35}$

Dental agenesis can also cause mouth breathing and narrow maxillary and mandibular arches, potentially resulting in SDB.${ }^{45}$ The growth of the alveolus (width, height, length) is dependent on the presence of the teeth. Lack of tooth development will produce an underdevelopment of the alveolar ridge with collapsibility of the dental arch. ${ }^{45}$ One such study of dental agenesis noted by Guilleminault et al. did not identify agenesis as part of a syndrome itself, but as an isolated finding. Thirty-one children with permanent teeth missing due to congenital agenesis and 11 children who had permanent teeth extracted all experienced a smaller overall oral cavity, leading to the collapse of the upper airway during sleep, resulting in POSA. ${ }^{45}$

Interestingly, not all cases with dental agenesis will in fact lead to OSA. In a retrospective study from Larsen et al., the authors discuss the long-term outcomes of OSA based on bicuspid extractions per-formed on 2,792 patients aged 40 to 70 years old. ${ }^{46}$ A total of 299 patients with 4 missing bicuspids from orthodontic therapy $(10.71 \%)$ received a diagnosis of OSA based on polysomnography. ${ }^{46}$ For patients in whom bicuspids were not missing, 267 $(9.56 \%)$ received a diagnosis of OSA, demonstrating no significant difference between both subject groups in whom OSA is diagnosed based on missing bicuspids. ${ }^{46}$ One limitation of this study is that the population was a typical age range for adults in whom OSA was diagnosed and does not take into account other involved comorbidities that could be contributing to their diagnosis. ${ }^{46}$

Although the study by Larsen et al. evaluates OSA in the adult population, it is relevant for practitioners 
evaluating extraction-based orthodontic treatment in children and adolescents. ${ }^{46}$ It would be interesting to look at cases of true agenesis in patients, such as ectodermal dysplasia, to identify the risks of POSA. This is because patients with ectodermal dysplasia show characteristics of a class III malocclusion with deficient maxillary growth, resulting in a decreased vertical dimension of occlusion affecting both sagittal and transverse growth of the jaws and soft tissues. ${ }^{47}$ These patients also have noted smaller pharyngeal and upper airway measurements with a more posteriorly positioned hyoid, which could influence the presence of POSA in this population. ${ }^{47}$

A high frequency of OSA is noted in dental patients with tooth wear (ranging from abrasion, attrition, erosion, and abfraction), therefore, there is a positive correlation seen between patients with severe bruxism and more severe symptoms of OSA as discussed in a prospective study by Durán-Cantollaet al. ${ }^{48}$ Up to one-half of children in whom POSA was diagnosed experience sleep bruxism, ${ }^{49,50}$ and two prospective studies have proved that an AT can alleviate the effects of sleep bruxism. ${ }^{49,51}$ In general, there is a twofold to threefold higher reported prevalence of OSA in patients with bruxism as found in a cross-sectional study using a telephone survey. ${ }^{52}$ Fifty percent of children experiencing tension-type headaches while undergoing polysomnography reported sleep bruxism versus only $2.4 \%$ of children without any headaches in a retrospective study by Vendrame et al. ${ }^{53}$ Given the association between POSA, headaches, and bruxism, dentists are then well positioned and can play an integral role in identifying children at risk for POSA and promptly refer these patients for earlier diagnosis and treatment. ${ }^{54,55}$

One additional factor that has emerged as an association between dental development and SDB is the duration of breastfeeding during infancy. Breastfeeding has many immunologic protective factors against viral infections and other immune-mediated responses that may contribute to development of chronic inflammation of the upper airway and hypertrophic lymphadenoid tissues, which can put a child at risk for future POSA. ${ }^{56}$ Montgomery-Downs et al. completed a retrospective survey from parents or guardians of 196 children (mean age: $6.7+/-2.9$ years) undergoing polysomnography in regard to their child's prior infant feeding patterns. ${ }^{56}$ The survey asked questions about a child younger than 12 months of age receiving formula only (no breast milk), breast milk only (no formula), or both formula and breast milk. ${ }^{56}$

The cohort consisted of $52 \%$ of children who were formula fed only, $10 \%$ breast fed only, and $38 \%$ fed a combination of both formula and breast milk with any child drinking breast milk having an average weaning age of 7.3 +/- 7.0 months. ${ }^{56}$ Following polysomnography and parental questionnaires, children who were breastfed for at least 2 months had significantly reduced measures of SDB severity including lower AHI and oxyhemoglobin desaturation nadir, and improved respiratory arousal index, implying that breastfeeding is protective against the development of SDB. ${ }^{56}$ However, breastfeeding for a period beyond 5 months did not provide any supportive benefits in regard to prevention of SDB. ${ }^{56}$

In another cohort study by Brew et al., the authors investigated the relationship between infant feeding practices, including any form of breastfeeding with and without formula (birth to 12 months of age), and SDB outcomes at the age of 8 years. ${ }^{57} \mathrm{~A}$ total of 450 of 616 children fully participated in the study, in which parents were asked about the duration of breastfeeding, with and without formula, as well as their child's sleeping habits. ${ }^{57}$ Snoring was found to be less common in children who were breastfed for longer than 3 months versus those infants who were breastfed for less than 3 months. ${ }^{57}$ A reduction in the overall risk of habitual snoring and apneas at age 8 years was associated with any breastfeeding for a period longer than 1 month, compared with breastfeeding for any duration less than 1 month. ${ }^{57}$ This study concludes that breastfeeding duration between 1 and 6 months is sufficient to protect children from the development of SDB. ${ }^{57}$

Breastfeeding appears to be protective against the development of malocclusions, due to encouraging proper mandibular formation, while also lowering the risk of SDB over bottle feeding. ${ }^{58,59}$ Another hypothesis relates to the discrepancies of feeding from the breast as opposed to the bottle. ${ }^{60}$ Breastfeeding involves a specific peristaltic motion of the tongue that is thought to be central to the development and coordination of the oropharyngeal musculature responsible for swallowing. ${ }^{60}$

In regard to protective factors that breastfeeding may have against developing malocclusion, a systematic review by Peres et al. reviewed 48 studies (most were cross-sectional) looking at breastfeeding versus no history of breastfeeding, exclusive breastfeeding versus nonexclusive breastfeeding, and the length of time for any type of breastfeeding, and compared these feeding practices with the developing occlusion in the primary dentition. ${ }^{61}$ Generally, a malocclusion was $70 \%$ less likely to develop in individuals who were breastfed compared to those who were breastfed for a short duration of time or were never breastfed. ${ }^{61}$ Overall, the systematic review found that breastfeeding practices also lowered the risk of development of malocclusion by $66 \%$, which may be preventive for the purposes of POSA ${ }^{61}$ In regard to exclusive versus nonexclusive breastfeeding, the risk of the development of malocclusion was lowered to $46 \%$ and that the longer the period of breastfeeding, the less likely malocclusion will develop $(60 \%){ }^{61}$

A systematic review by Doğramac1 et al. included seven studies to support the findings that that children without appropriate breastfeeding practices exhibit a higher risk for the development of malocclusion in the realm of class II canine relationship (shorter duration of breastfeeding), anterior open bite (non-breastfed), and posterior crossbite (non-breastfed). ${ }^{62}$ Nine studies found in a systematic review by Boronat-Catala et al. showed that breastfeeding 
Table 1. Surgical therapies for OSAS in children

\begin{tabular}{lll}
\hline Therapy & Population & Benefits \\
\hline $\begin{array}{l}\text { Adenotonsillectomy } \\
\text { (AT) }\end{array}$ & $\begin{array}{l}\text { Children with enlarged ton- } \\
\text { sils and/ or adenoids }\end{array}$ & $\begin{array}{l}\text { Highly effective; well-tolerated } \\
\text { in most children }\end{array}$
\end{tabular}

Adenotonsillectomy

Partial tonsillectomy

(PT) and adenoidec-

tomy

Lingual tonsillectomy

Persistent OSAS after AT

with enlarged lingual tonsils

Children with enlarged tonsils \pm adenoids

Tracheostomy

Bariatric Surgery

Craniofacial surgery
Children with severe OSAS and no other therapeutic option

Select obese teenagers that have failed other therapies

Select children with craniofacial conditions
Shorter recovery time than extracapsular tonsillectomy

Definitive therapy for residual OSAS

\section{Risks/challenges}

Common: pain, decreased oral tolerance, rarely hemorrhage, respiratory complications, etc.

Efficacy in treating OSAS less- established; effect of tonsillar regrowth on OSAS unknown

Concentric scarring in airway; efficacy/ideal population not well-established in OSAS

Highly effective

Requires increased monitoring at home; increased risk of significant complications

Small studies show high short term success rate in select populations

Highly effective in select populations
Significant complications; no longterm efficacy data, success varies by center/type of surgery

Minimal long-term follow-up data; success varies by center/type of surgery; significant morbidity

Reprinted from Cielo CM, Gungor A. Treatment Options for Pediatric Obstructive Sleep Apnea. Curr Probl Pediatr Adolesc Health Care.2016;46(1):27-33

longer than 6 months and breastfeeding in any manner (especially exclusively) showed a decreased rate of the development of posterior crossbites as well as class II malocclusion. ${ }^{63}$ These findings again support the notion that breastfeeding is protective against developing harmful malocclusions, which could contribute in the prevention of POSA.

However, a systematic review by Abreu et al. concentrated on the link between breastfeeding versus bottle feeding with effects on the development of occlusion in mixed and permanent dentition through a close examination of six cross-sectional studies. ${ }^{64}$ This review found that there is not enough evidence to show that breastfeeding can help reduce the incidence of malocclusion in both mixed and permanent dentitions. ${ }^{64}$ One of the six cross-sectional studies found a parallel effect between breastfeeding and bruxism, thereby increasing the risk for a class II or III malocclusion. ${ }^{64}$ In addition, cephalometric analysis showed that children breastfed for longer than 6 months were more likely to have proclined mandibular incisors and inclination of maxillary incisors in contrast with those who were only breastfed for less than 6 months and for those children who were bottlefed. ${ }^{64}$

Therefore, there may not be enough evidential support to promote breastfeeding, especially for longer than 6 months in prevention of malocclusion because the authors of this review were not able to separately group children who were exclusively breastfed, or had mixed feeding practices, or bottle fed, and the data may be somewhat inaccurate because it relies on subjective parental response with surveying the feeding practices. ${ }^{64}$

In conclusion, breastfeeding appears to assist in formation of healthy jaw structure while also decreasing the likelihood of craniofacial aspects associated with SDB (dolichofacial form, palatal constriction with crossbite, teeth crowding, and increased overjet) from evolving ${ }^{56,57}$ as well as promoting a healthy upper airway growth that is less prone to maxillary arch collapse during sleep. ${ }^{56} \mathrm{In}$ addition, breastfeeding may provide additional immunological protection against development of SDB by reducing hypertrophy of upper respiratory inflammatory tissue.

Sleep disordered breathing has a negative contribution on the overall growth and development of children. ${ }^{65}$ Therefore, early screening of infants to assess for tongue or lip tie, breastfeeding practices (which promotes positive development of the orofacial musculature), and elimination of non-nutritive habits such as pacifier or digit sucking, are proper steps in ensuring proper development of the child. ${ }^{65}$

\section{TREATMENT CONSIDERATIONS}

For purposes of simplicity, treatment for POSA is divided here into surgical and nonsurgical methods. The decision as to which modality is pursued is dependent on the severity and etiology of the patient's POSA and in the case of nonsurgical treatment, the patient's compliance, ${ }^{2}$ and 
thus may involve a combination of both surgical and nonsurgical techniques.

\section{Surgical Options}

Generally, the first line of therapy in the treatment of POSA consists of surgically removing the hypertrophic adenoids and tonsils. ${ }^{66}$ When a tonsillectomy occurs with adenoid removal the procedure is then considered as AT. ${ }^{67}$ If POSA has been diagnosed in a child, and if a child has adenotonsillar hypertrophy, unless contraindicated, AT is considered first-line therapy (Table 1). ${ }^{67}$ AT can be successfully used in most children with POSA, however, retrospective studies have found that older children with obesity and those with more severe preoperative POSA are more likely to have incomplete resolution of POSA following AT. ${ }^{68-70}$ In patients identified with small tonsils and adenoids, morbid obesity with small tonsils/adenoids, or an un controlled bleeding disorder, AT is contraindicated. ${ }^{67}$

In a retrospective chart review by Spencer and Jones, 93\% of patients reported no intraoperative or postoperative problems following an AT, making it a safe procedure overall. ${ }^{71}$ Complications following AT comprise a range from mild symptoms such as reduced oral intake and pain, whereas more severe outcomes including postoperative bleeding, dehydration, infection, respiratory difficulties, and even atlantoaxial subluxation may also exist. ${ }^{67}$ A casecontrol study by Gallagher et al. discussed the rate of these more complicated consequences, including hemorrhage and dehydration ranging from $0.7 \%$ to $3.1 \% .^{72}$ However, a recently published meta-analysis by De Luca Canto et al. has revealed that AT complications, particularly respiratory complications, are more common in children with POSA and even more specifically, children with POSA are nearly five times more likely to develop a respiratory complication following $\mathrm{AT}^{73}$

In the CHAT, 464 children aged 5 to 9 years of age (mean age was 6.5 years) from 7 academic sleep centers in whom POSA was diagnosed were either assigned to an early AT group $(\mathrm{N}=226)$ or a "watchful waiting" group $(\mathrm{N}=227) .{ }^{42}$ Polysomnographic, cognitive, behavioral, and health outcomes were assessed at baseline and at 7 months. ${ }^{42}$ Developmental Neuropsychological Assessment (NESPY) "scores range from 50 to 150, with 100 representing the population mean, and higher scores indicating better functioning and executive-function score". ${ }^{42}$ The AT group showed remarkable improvements in behavioral, quality-of-life, and polysomnographic findings as well as with overall symptoms of POSA. ${ }^{42}$ As far as attention and executive-function scores on the NESPY, no significant differences were observed between the two groups at baseline or at follow-up. ${ }^{42}$ Also, this study is in agreement with other studies that African-American children may benefit from early treatment with an AT, versus monitoring POSA signs/symptoms, as they typically display more severe cases of POSA than other racial groups. ${ }^{42}$

Although AT is considered the first-line surgical therapy, it has proven to have diminishing results in some longterm studies. Studies have revealed that, over the long term, $50 \%$ of children with obesity and $10 \%$ to $20 \%$ of children without obesity will still have residual signs and symptoms of POSA following an AT. ${ }^{44,74,75}$ In children with POSA, a multicenter study by Bhattacharjee et al. showed a $27 \%$ cure rate with AT, therefore, this is not a cure-all procedure. ${ }^{10}$ Moreover, obesity significantly reduces the efficacy of AT in treating POSA. ${ }^{10,42}$ Given recent findings, it is becoming more apparent that additional surgical and/or nonsurgical strategies are indicated to resolve POSA.

One such surgical strategy includes maxillomandibular advancement. A recent meta-analysis by Holty and Guilleminault shows that in the adult population, younger age (although this was not defined in the study) has better results for maxillomandibular advancement in the treatment of OSA based on presurgical and postsurgical polysomnography results ${ }^{76}$, however, this surgical procedure is not well studied in children. This is most likely due to the invasive nature of the surgery and risks that are imposed, including disrupted intrinsic mandibular growth and potential damage to the inferior alveolar nerve. ${ }^{77}$ Patients with Pierre Robin sequence or Treacher Collins syndrome are more likely to undergo this aggressive therapeutic surgery to help alleviate the severe retrognathia associated with these conditions. ${ }^{77}$

Magliocca and Helman revealed that maxillomandibular advancement of $10 \mathrm{~mm}$ was found to be $90 \%$ successful in adult patients, average age 41 years, with a BMI $<32$ $\mathrm{kg} / \mathrm{m}^{2}$, but was only $60 \%$ effective in patients with a BMI $>32 \mathrm{~kg} / \mathrm{m}^{2}{ }^{78}$ Patients with significant obesity and severe OSA who underwent bimaxillary distraction osteogenesis of $25 \mathrm{~mm}$ showed a $100 \%$ effective result in a small cohort of 9 patients. ${ }^{78}$ Again, these studies are limited to adults only.

Other surgical options, more commonly performed in adult patients with OSA, include uvulopalatopharyngoplasty (UPPP), ablation, revision of previous posterior pharyngeal flap surgery, distraction osteogenesis, or tracheostomy as noted in Table $1 .^{2,67}$ However, there is a general reluctance to use these surgical procedures in growing children, with the possible exception of children with underlying craniofacial abnormalities.

The UPPP procedure is estimated to be only $40 \%$ to $50 \%$ successful in improving mild to moderate OSA. ${ }^{79}$ Its effectiveness decreases over time, adding substantial postoperative complications including velopharyngeal insufficiency (reported at 2\%), postoperative hemorrhage (reported at $1 \%$ ), continued dryness of the airway, dysphagia, voice change (reported at $0.6 \%$ ), narrowing of the nasopharyngeal walls (reported at $0.8 \%$ ), and death (reported at $0.2 \%) .{ }^{79}$ A revision of this technique is called a uvulopalatal flap and is actually preferred over UPPP in most cases 
Table 2. Non-surgical therapies for OSAS in children

\begin{tabular}{|c|c|c|c|}
\hline Therapy & Population & Benefits & Risks/challenges \\
\hline $\begin{array}{l}\text { Positive airway pres- } \\
\text { sure (PAP) }\end{array}$ & Any child & $\begin{array}{l}\text { Strong evidence for efficacy, } \\
\text { even if OSAS severe }\end{array}$ & $\begin{array}{l}\text { Some will have trouble tolerating; few } \\
\text { mask options for some children }\end{array}$ \\
\hline $\begin{array}{l}\text { Nasal steroids and } \\
\text { leukotriene receptor } \\
\text { antagonists }\end{array}$ & $\begin{array}{l}\text { Children with mild-moderate } \\
\text { OSAS }\end{array}$ & Minimally invasive & $\begin{array}{l}\text { Weak evidence; length of therapy } \\
\text { needed/ideal population unclear }\end{array}$ \\
\hline $\begin{array}{l}\text { Rapid maxillary ex- } \\
\text { pansion/oral appli- } \\
\text { ances }\end{array}$ & $\begin{array}{l}\text { Children with narrow maxilla } \\
\text { or constricted maxillary arch, } \\
\text { non-obese, without ade- } \\
\text { notonsillar enlargement }\end{array}$ & $\begin{array}{l}\text { Therapy is short term, minimally } \\
\text { invasive, may be easier to toler- } \\
\text { ate than PAP }\end{array}$ & $\begin{array}{l}\text { Few studies showing efficacy; unclear } \\
\text { which children will benefit most; dis- } \\
\text { comfort; potentially expensive }\end{array}$ \\
\hline Supplemental oxygen & $\begin{array}{l}\text { Unclear; possible infants or } \\
\text { those with no other thera- } \\
\text { peutic options }\end{array}$ & May prevent hypoxemia & $\begin{array}{l}\text { Dose not treat airway obstruction; risk } \\
\text { of hypercapnia }\end{array}$ \\
\hline Weight loss & Older, obese children & $\begin{array}{l}\text { Non-invasive, good for overall } \\
\text { health; can be done in conjunc- } \\
\text { tion with PAP }\end{array}$ & $\begin{array}{l}\text { Difficult, no evidence for sustained } \\
\text { resolution of OSAS }\end{array}$ \\
\hline
\end{tabular}

Reprinted from Cielo CM, Gungor A. Treatment Options for Pediatric Obstructive Sleep Apnea. Curr Probl Pediatr Adolesc Health Care.2016;46(1):27-33

because it lowers the risk of velopharyngeal insufficiency as it creates a potentially reversible flap that can be altered during the initial postoperative period. ${ }^{79}$ Because there are no sutures involved along the free edge of the palate, there is less reported pain in comparison with UPPP, however, this technique still imposes the same risks of complications as seen with UPPP and is typically performed on adults only. $^{79}$

Ablation has the advantage over electrocautery and laser applications because of its lower temperature, safety, and overall precision without affecting speech or swallowing. ${ }^{79}$ The only downside to this technique is that it requires multiple treatments over weeks, and although uncommon, may result in ulceration and infection. ${ }^{79}$

Distraction osteogenesis, by way of rapid maxillary distraction combined with an AT, has proved to be successful in treating children with OSA with the following facial features: high arched palate and a unilateral or bilateral posterior crossbite in patients who are at least 5 to 16 years old (before the cartilage becomes bone). ${ }^{79}$ As discussed previously, syndromic patients may benefit from mandibular distraction osteogenesis by expanding the bones in the mandible via internal or external fixation (external fixation results in more scarring). ${ }^{79}$ These distraction strategies work by allowing increased space for the tongue to lie so that it does not fall posteriorly and obstruct the oropharynx. ${ }^{79}$ Rapid maxillary distraction may be performed in congruence with mandibular distraction osteogenesis when the patient has reached the age of adolescence (approximately 12 to 13 years). ${ }^{79}$

Tracheotomy is the most aggressive of the aforementioned techniques, but is suggested as a cure for OSA as it evades the upper airway, however, it is associated with significant social and morbidity risks including infection of the stoma $(36 \%)$, hemorrhage $(5 \%)$, tracheal stenosis (2\%), and psychosocial difficulties. ${ }^{79}$ This surgical method is more of a temporary solution in protecting the airway in patients with severe sleep apnea due to comorbidities including morbid obesity and craniofacial syndromes. ${ }^{79}$ It may be used as a last resort for patients who have undergone other unsuccessful surgical and nonsurgical procedures. $^{79}$

Finally, bariatric surgery may represent a viable therapeutic option to treat OSA in the morbidly obese adult patient, ${ }^{80}$ but the evidence to support its use to treat POSA is sparse. In the systematic review by Ashrafian et al., the authors concluded that both bariatric surgery (19 studies) and nonsurgical treatments for obesity (20 studies) may reduce the effects of OSA by lowering BMI and AHI, suggesting that bariatric surgery results in more optimal improvement in both BMI and AHI, as well as improving the symptoms associated with OSA. ${ }^{80}$

\section{Nonsurgical Medical Considerations}

As measures to diagnose POSA have evolved, so have treatment modalities including several nonsurgical approaches that in some cases replace or serve as an adjunctive to AT. Because obesity is the second most common cause of POSA, weight reduction is a common nonsurgical recommendation for these patients. However, other therapeutic strategies may be used concurrently to address the patient's POSA while weight reduction is pursued.

Nonsurgical treatment options include PAP, myofunctional therapy, and if indicated, maxillary expansion along with other dental/orthodontic treatment ${ }^{2,67}$ (Table 2). 
This highlights the need for multidisciplinary approaches to the treatment of POSA. Teams consisting of primary care physicians, otolaryngologists, sleep medicine physicians, myofunctional therapists, and dentists (including general dentists, pediatric dentists, and orthodontists) have become much more common. ${ }^{2}$ This approach focuses on prevention and early intervention in the treatment of POSA, with the goal of establishing or reestablishing effective nasal breathing in affected patients.

Therapy with PAP is often considered the next treatment strategy if AT is not effective or if POSA remains unresolved after AT. ${ }^{67}$ Positive airway pressure works via an electronic device through a nasal or oronasal mask, acting as a stent to open the airway during sleep. ${ }^{67}$ It is classified as continuous positive airway pressure (CPAP) or as bilevel pressure (BPAP) ${ }^{67}$ Adherence with PAP is often a challenge for patients, despite its overall effectiveness in resolution of POSA as analyzed through various prospective and retrospective studies. ${ }^{81-83}$

In a retrospective review by Hawkins et al., patients with POSA were followed by the hospital in a documented in-laboratory CPAP titration study with CPAP initiation or adjustment and adherence data obtained between February 1, 2013, and February 1, 2014. ${ }^{84}$ One hundred forty patients, 54\% male, with a mean age of 12 years old, mostly white and Hispanic, were evaluated for adherence with CPAP. In summary, this study found $49 \%$ adherence with 7.4 hours of use per night, and females $(60.9 \%)$ were noted to be more adherent than males $(39.5 \%)$ with no differences in age, ethnicity, or insurance status. ${ }^{84}$ This study revealed that adherence to CPAP therapy is poor but suggested that female sex and developmental delay are associated with better overall adherence. ${ }^{84}$ In general, CPAP compliance is even more difficult in patients who present with atopy, asthma, or allergic rhinitis. ${ }^{84}$

In another study led by Ramirez et al. examining adherence of CPAP versus BPAP, 62 children (mean age, 10 \pm 5 years) were studied consisting of children with POSA $(n=51)$, neuromuscular disease $(n=6)$ or lung disease $(n=$ 5). ${ }^{85}$ Mean reported adherence was $8.17 \pm 2.30$ hours per night with no significant differences noted between CPAP and BPAP groups. ${ }^{69}$ Seventy-two percent of the patients used their CPAP/BPAP device more than 8 hours per night and the mean number of nights during the last month of use was $26 \pm 5 .{ }^{85}$ The total duration of CPAP/BPAP treatment, age of patient, type of underlying medical condition, the type of mask or cannula used, or nightly gas exchange did not correlate with adherence. ${ }^{85}$

Adherence and proper fit of equipment are typically the largest obstacles in treating children with PAP. ${ }^{67} \mathrm{Lim}-$ itations in size of masks being available to treat children (especially those younger than 2 years) in whom POSA was diagnosed, as well as children with craniofacial malformations pose additional challenges in PAP adherence. ${ }^{67}$ Behavioral therapy including motivational training may increase overall acceptance to PAP in children. ${ }^{86,87}$ In a qualitative study by Prashad et al., "PAP adherence may be influenced by perception of benefit, degree of structure in the home, and social reactions, among other factors". 88

Another nonsurgical treatment modality comprises the use of upper airway anti-inflammatory medications including leukotriene receptor antagonists such as montelukast with or without intranasal steroids. These medications may be particularly effective for treatment, especially in children with nasal allergies that contribute to POSA symptoms. In mild POSA, or cases where there is adenoidal regrowth following AT, or when AT cannot be performed, intranasal steroids are often indicated. ${ }^{67}$ One such case report found the overall obstructive AHI to decline from $10.7 \pm 2.6$ hours to $5.8 \pm 2.2$ hours in the treatment group when children were randomized to receive a nasal corticosteroid, nasal fluticasone propionate. ${ }^{89}$ Also, intranasal budesonide was shown to improve polysomnographic findings in a double-blind, randomized crossover trial by Kheirandish-Gozal and Gozal, but did not provide finite elimination of POSA. ${ }^{90}$ The rationale for these approaches centers on the premise that these therapies reduce the inflammatory proliferation of adenotonsillar tissue, which often leads to a reduction in their size..$^{91,92}$ A potential limitation for this treatment modality is that children are at risk for growth and adrenal disturbances if intranasal steroids are used for extended periods of time, and cause unwanted side effects including nasal irritation and epistaxis. ${ }^{67}$

Studies utilizing combination therapy with montelukast and intranasal steroids, such as budesonide in patients with unresolved POSA following AT, have had positive results, showing even further reductions in AHI. ${ }^{93}$ Sixty-two percent of 445 patients in whom mild POSA was diagnosed who were treated with this same combination of medications by the same group of researchers via a retrospective design showed complete resolution of POSA. ${ }^{36}$

Although weight loss as a viable strategy to treat adult OSA has been extensively studied, ${ }^{94}$ data pertaining to pediatrics are limited, likely secondary to the inherent challenges of treating pediatric obesity. Verhulst and colleagues studied 37 subjects with obesity and POSA, of whom 21 had repeat sleep studies following weight loss. ${ }^{95}$ There were significant improvements in several polysomnographic parameters of SDB. In fact, only 8 of 21 subjects $(38 \%)$ were found to have residual POSA. ${ }^{95}$

\section{Nonsurgical Dental Considerations}

One nonsurgical approach that could be considered is screening for OSA through biomarkers. Through a metaanalysis by De Luca Canto et al., the authors investigated biomarkers through blood, saliva, urine, and exhaled breath condensate in both adults and children with OSA. Overall, pediatric studies did not show a specific biomarker to aid in diagnosis of POSA but interleukin 6 and interleukin 10 
are proving to be potential biomarkers in recognizing OSA in the adult population. ${ }^{96}$ Biomarkers including kallikrein1, uromodulin, urocortin-3, and orosomucoid-1 appear to be potential markers for screening OSA in children. ${ }^{96}$

De Luca Canto et al. also looked at comorbidities associated with OSA through blood biomarkers where the team of authors evaluated 48 articles (34 in adults and 14 in children). ${ }^{96}$ Many cardiovascular, endocrine, and neurological manifestations may be coexistent with OSA. ${ }^{96}$ Throughout the systematic review, the authors concluded that interleukin 6 and high-sensitivity C-reactive protein (inflammatory marker) show promise as biomarkers in differentiating children and adults with OSA who have associated comorbidities versus those who do not exhibit comorbidities. ${ }^{96}$ Myeloid-related protein 8/14 (cardiovascular morbidity marker) can be found as a comorbidity expressed in children with POSA. ${ }^{96}$ Neurological status in regard to cognitive abilities may be better understood through urinary neurotransmitters in the pediatric population. ${ }^{96}$ With the use of these specific biomarkers, underlying comorbidities may be detected in patients with OSA. ${ }^{96}$

Additional research looking at these promising biomarkers, especially in the pediatric population, is fundamental as children who present with a normal polysomnography with primary snoring may be very symptomatic and vice versa ${ }^{97}$ The AHI score attained from polysomnography is typically used to help diagnose OSA, however, the cutoff value for a normal AHI is not very clear in pediatric patients and no agreement has been reached for an AHI cutoff rendering the need for an AT. ${ }^{96}$ Although polysomnography is the gold standard for diagnosing OSA in populations of all ages, the caveat is the long wait time in receiving the test, erroneous results, and high cost involved. ${ }^{97}$

Biomarkers may alert the clinician to look for other probable markers that polysomnography may not capture and help reduce costs associated with polysomnography. Study authors suggest that biomarkers are one-fourth the cost of polysomnography when screening patients for OSA through the utilization of biomarkers prior to testing with polysomnography. ${ }^{96}$

In 2005, the American Academy of Sleep Medicine (AASM) published updated guidelines that support oral appliance therapy (OAT) "as a first-line therapy for mild and moderate OSA". ${ }^{98}$ Once a thorough medical examination is completed by a physician, a dental referral for OAT can be made. ${ }^{99}$ The identification, diagnosis, and treatment of sleep disorders with OAT are areas where both dentists and physicians must work collaboratively for the benefit of the patient. ${ }^{99}$ By widening the upper airway with or without lessening the collapsibility of the airway, oral appliances can help improve opening the airway during sleep, which also improves the overall quality of the muscular tone. ${ }^{100} \mathrm{~A}$ clinical trial by Cozza et al. showed that the modified monobloc appliance in children may be considered as an effective approach in the treatment of mild to moderate
POSA. ${ }^{101}$

Rapid maxillary expansion (RME), also known as rapid palatal expansion, can be used in the process of expanding the upper airway to alleviate a patient's POSA. ${ }^{102}$ In a recent meta-analysis by Camacho et al., the authors found that RME produced a decreased $\mathrm{AHI}$ in children with POSA (mean age 6 to 8 years), but can widen the midpalatal suture through the teenage years. ${ }^{102}$ In a total of 313 patients, the overall AHI decreased from a mean \pm standard deviation of $8.9 \pm 7.0 / \mathrm{hr}$ to $2.7 \pm 3.3 / \mathrm{hr}$, resulting in a $70 \%$ improvement in the AHI. ${ }^{102}$ The authors concluded that patients with smaller tonsil size (Brodsky 1) could benefit from primary treatment of POSA with RME and it could also be used in patients with failed AT in the context of narrow, arched palates. ${ }^{102}$

In a cohort study by Villa et al., the investigators report that RME was effective beyond 2 years following treatment in children in whom a combination of malocclusion and POSA was diagnosed. ${ }^{103}$ In an older study by Timms in 1974, children treated with RME experienced resolution of nocturnal enuresis. ${ }^{104}$ Mandibular advancement and RME are able to improve patient swallowing because they help guide the tongue to the correct position while also counterbalancing the occlusion. ${ }^{105}$ Guilleminault et al. presented a small cohort in which most children in their study had satisfactory resolution of POSA as well as normalization of polysomnography following RME combined with adenoidectomy. ${ }^{106}$ Due to inconclusive evidence in the literature, RME cannot be recommended to treat patients having breathing problems with normally developed maxillary arches. ${ }^{107}$

In a recent Cochrane review by Carvalho et al., the authors looked at the effects of oral appliances in the treatment of POSA compared to no treatment or placebo. ${ }^{108}$ The authors only discovered one study by Villa et al. in 2002, a quasi-randomized control study, that looked at the AHI of 32 children (20 male, 12 female) with a mean age of $7.1+/-2.6$ years following treatment with an oral appliance versus no appliance therapy. ${ }^{109}$ If the patient was designated to receive an appliance, it was delivered to the patient following the second polysomnography test. ${ }^{109}$ The authors defined a $50 \%$ decrease in the AHI following appliance therapy to be successful for the purposes of this study; therefore, 9 of the 14 treated with appliance therapy reached a $50 \%$ decrease in the AHI, and had overall improvement in nighttime and daytime symptoms. ${ }^{109}$

However, due to the low quality of evidence from this one study (as it was not nonrandomized in distribution or with no disguise in distribution, no blinding, no sample size calculation reported, and finally, the number of patients randomized was different from the number of patients analyzed due to loss of patient follow-up, etc), this further suggests that future clinical trials on problems with malocclusion or respiratory illness should include information and results about how to improve respiratory and malocclusion problems in both medical and dental fields. ${ }^{108}$ For 
instance, as one physician attempts to correct a respiratory disease, malocclusion may still persist and cause weakening respiratory issues over time if malocclusion is not corrected and vice versa. ${ }^{108}$

Machado-Junior et al. reviewed the literature on children treated with RME to resolve symptoms of POSA through a systematic review using 10 articles to discover that in 215 children with a mean age of 6.7 years, the mean AHI significantly decreased. ${ }^{110}$ With careful repositioning of the tongue (raising its posture), RME can in return increase the maxillary width and properly seal the lips, which diminishes mouth breathing and the size of the tonsils. ${ }^{110}$ Hence, RME is successful in increasing the size of the intranasal cavity by improving the overall oxygen saturation by producing better quality airflow in the nasal cavity; this in turn causes less mouth breathing (particularly in patients with smaller tonsil sizes). There is notably increased transverse maxillary width to allow for better positioning of the tongue in the oral cavity, which may improve the positioning of the teeth within the arches for better arch development. 108

Huynh et al. explored six studies via meta-analysis to determine the effects of RME or orthomandibular advancement in addition to both procedures combined in children younger than 18 years to detect whether these therapies are effective in reducing POSA. ${ }^{111}$ Overall, a lowered AHI score was noted upon completion of treatment with any of the procedures used alone or in combination. ${ }^{111}$ Because of the small sample sizes noted in the various literatures reported in this review, more studies are recommended to confirm the results. ${ }^{11}$

Mandibular repositioning appliances (MRAs) are often restricted to the treatment of adults with OSA, due to limited available evidence in children. ${ }^{112}$ The valued range of protrusion obtained from an MRA is effective at 6 to 10 $\mathrm{mm}$ or is noted at $65 \%$ to $70 \%$ of "maximum protrusive potential". ${ }^{112}$ With a titratable MRA, it would allow for slow advancement while also lowering the risk of potential side effects including temporomandibular disorders (TMD) or muscular tension. ${ }^{112}$

Mandibular advancement appliances (MAA) may expand the oropharynx in a lateral direction by protruding the mandible by way of stimulating the activity of the genioglossus muscle. This in return lowers the risk of airway collapse and promotes positive skeletal development. A systematic review that included four articles evaluated by Nazarali et al. found that MAAs used for the treatment of POSA will likely result in short-term improvements in lowering AHI, therefore, the authors did not find it appropriate to conclude that these devices are applicable in treating the pediatric population. ${ }^{113}$ Compliance in wearing a nonfixed versus fixed MAA can be a major influence on the results of the AHI scores in the studies that were reviewed as well as the extent of mandibular retrognathia. ${ }^{113}$ In conclusion, the studies represented in the systematic review in the literature included small sample sizes, lack of randomization, and lack of control groups. ${ }^{113}$ Perhaps more research is needed in order to investigate the plausibility of MAAs in the treatment of POSA. ${ }^{113}$

Following treatment with OAT, an additional sleep study is recommended to determine whether it has reduced the AHI. ${ }^{114}$ The long-term data on RME in treating POSA is very limited as relapse is observed over a period of over 6 years following treatment with RME in teenagers per a retrospective analysis by Guilleminault et al., which could in fact be due to skeletal relapse following RME treatment. ${ }^{115}$ Additional studies with randomized controlled trials over a longer study period would be pertinent in understanding the effect of RME on the treatment of POSA and potential relapse. ${ }^{115}$ Accordingly, dentists prescribing OAT need to be well versed in pediatric SDB and have an understanding of its diagnostic testing. ${ }^{114}$

To determine whether a patient is a candidate for OAT, the dental examination should include a caries risk assessment, periodontal examination, and a temporomandibular joint evaluation to include the muscles of mastication, occlusal analysis, and parafunctional habits, ${ }^{112}$ as well as consideration for possible orthodontic evaluation. Parafunctional habits including sleep bruxism may also be a symptom of POSA. ${ }^{27}$ Sleep disordered breathing has also been associated with a variety of oral and craniofacial problems that may be revealed during a dental examination. Factors such as degree of mandibular retrusion, class II malocclusion, and/or a retrusive chin may contribute to the patient's SDB. ${ }^{103,27}$ Likewise, the examination may reveal maxillary constriction, a long and narrow face, a narrow upper airway, or an increased vertical direction of growth. ${ }^{27,103}$

Early studies suggest that a cephalometric radiograph can help predict success with oral appliances or monitor for craniofacial changes with an appliance's use over time. ${ }^{112}$ An observational study by Sakat et al. reported that cephalometric measurements of the inferior position of the hyoid bone was one of the most fundamental factors seen in patients with OSA, and SNA and SNB angles were significantly decreased in the patients with OSA compared with the control group. ${ }^{116} \mathrm{~A}$ systematic review by Flores-Mir et al. described common findings across various studies to include a narrow maxillary dental arch with a high palatal vault, posterior crossbite, longer and lower anterior facial height, steep mandibular plane angle, clockwise rotation of the mandible, and a retrusive chin to be craniofacial morphological characteristics to be concerned about with regard to POSA. ${ }^{117}$

However, there are limitations in diagnosing POSA using cephalometric analysis because of the low resolution caused by soft tissues and the fact that the postural position taken by the patient is not representative of the actual position the patient has while sleeping as shown in a systematic review by Patini et al. ${ }^{118}$ A systematic review by Major et al. looked at children aged 3 to 18 years old in regard to various imaging techniques of tonsillar hypertrophy among 
7 articles that met the search criteria. ${ }^{119}$ Overall, cephalometrics provided fair to good sensitivity (authors used the following ranges for sensitivity to assess a higher rate of false positives: excellent, $>80 \%$; good, $70 \%$ to $79 \% .^{119}$ Excellent and fair to good sensitivity had a wide margin of specificity pending the technique used (authors used the following ranges for specificity to assess a lower rate of false negatives: excellent: $>90 \%$; good: $80 \%$ to $89 \% .^{119}$

In conclusion, adenoid size may be overestimated if using lateral cephalometry as a diagnostic tool, as it tends to produce better accuracy in evaluating airway patency. ${ }^{119}$ Cone beam computed tomography is able to provide an accurate three-dimensional image of the airway with the added benefit of reducing the patient's overall radiation exposure versus conventional cephalometric radiography. ${ }^{120}$

An interesting aside to appliance therapy in patients with OSA concerns those who exhibit bruxism while sleeping. A prospective study by Durán-Cantolla et al. found a positive relationship between the severity of tooth wear and the severity of OSA. ${ }^{48}$ For patients with bruxism, some hypothesize that the activity of teeth grinding presents as a motor protective reflex to prevent airway collapse. ${ }^{121}$ There is limited evidence at this time for effective treatment of sleep bruxism in children as it may fall under a category of physiologic parafunctional activity that may need close monitoring and follow-up. ${ }^{122}$

Parasomnias are disorders that fall directly under the activation of the central nervous system by inducing activity of the skeletal muscle or autonomic nervous system. In theory, these parasomnias could be driven by abnormal movements, behavior, dreaming, emotions, and autonomic nervous system functioning captured during sleep. ${ }^{123}$ Conventional treatment approaches may include behavioral modifications, biofeedback, sleep hygiene, and familial counseling on sleep habits, and treatment with an occlusal guard for more severe cases involving temporomandibular joint disturbances. ${ }^{122}$ In $8 \%$ to $38 \%$ of children sleep bruxism has been diagnosed the condition has frequently been associated with SDB, in particular with snoring, headaches, and POSA, suggesting the benefit of a multidisciplinary approach for the management of POSA. ${ }^{122}$

This finding is in contrast to a systematic review completed by De Luca Canto et al. that did not support the association between sleep bruxism and SDB through one article chosen that met the authors' search criteria (also a small sample size of 21 patients with an average age of 40 years and no control group). ${ }^{123}$ Therefore, this systematic review only depicts one article's assessment using the article from Sjoholm et al. ${ }^{124}$ The finding of this study reported that the activity of the masseter muscle was not present during periods of apnea, and activity of the temporal muscles was not detected during periods of apnea or with snoring, hence, no link existed between SDB and sleep bruxism. ${ }^{124}$ However, the data could explain that bruxism is most commonly involved with body movement via isolated arousals, although bruxism is commonly reported with SDB. Even though apneic-hypopneic events will produce arousals from sleep, they do not appear to be in sync with sleep bruxism, which could prove that an isolated arousal does not seem to cause sleep bruxism. The authors suggest evaluating a patient's occlusion versus relying on sleep bruxism in relation to screening for SDB. ${ }^{123}$

Unfortunately, OAT is not well studied in children and dental insurance companies may not cover the cost of this particular treatment modality. Currently there are dental codes for "fixed appliance therapy" as well as "removable appliance therapy" falling under the realm of orthodontic procedures. Therefore, depending on state and insurance guidelines, coverage for OAT may require treatment by an orthodontist versus the general dentist or pediatric dentist. This then potentially limits the number of providers being able to treat children with POSA. Appliances for habits such as bruxism fall under "occlusal guards by report" or "lab occlusal guard-nightguard". Utilizing OAT appliances for myofunctional purposes or bruxism is typically not a current covered benefit for patients, making it difficult for parents to endure an out-of-pocket expense for their child.

Myofunctional therapy is an approach that has been used for at least 40 years. It aims to strengthen the muscles of the tongue and orofacial structures by educating patients on how to reposition their muscles to the correct position. ${ }^{115}$ Until recently, it is rarely considered to utilize myofunctional therapy in the treatment of POSA, even though there are supporting data pointing to the positive relationships noted between the development of the oropharynx and orofacial muscles that may be collapsing with POSA. ${ }^{115}$ Therefore, it would seem that oral myofunctional therapy should be considered a routine part of a comprehensive approach in the treatment of POSA to facilitate in the proper oropharyngeal development of a child. ${ }^{65}$ Nasal breathing and lip seal as well as lip tone are factors involved in the treatment by orofacial myologists. ${ }^{65}$ Myofunctional therapy includes exercises in nasal breathing, labial seal, lip tone, and tongue posture that can be performed at a repetition rate of 10 to 20 times, three times a day, with the goal of reestablishing nasal breathing and lip seal. ${ }^{65}$ A recently published meta-analysis by Camacho et al. evaluated nine studies in adults and just two studies in children that demonstrated that myofunctional therapy decreases AHI by approximately $50 \%$ in adults and $62 \%$ in children. ${ }^{125}$

Finally, it is important to emphasize that the American Sleep Disorders Association states, "the presence or absence of OSA must be determined by a qualified physician before initiating treatment with oral appliances to identify those patients at risk due to complications of sleep apnea, and to provide a baseline to establish the effectiveness of subsequent treatment". ${ }^{99}$ Treatment of SDB by oral appliances should be a team approach. Civil and criminal liability put the practitioner at risk if they exceed the scope of professional license; therefore, adequate diagnosis and 
Table 3. Conclusions-Sleep Disorders and Sleep Deprivation: An Unmet Public Health Problem

- The public health burden of chronic sleep loss and sleep disorders is immense

- Awareness among the general public and health care professionals is low

- The available workforce of health care providers is not sufficient to diagnose and treat individuals with sleep disorders

- There is a need to develop and reorganize public health and academic sleep programs to facilitate and improve the efficiency and effectiveness in public awareness, training, research, diagnosis, and treatment of sleep loss and sleep disorders

- The fragmentation of research and clinical care currently present in most academic institutions requires the creation of accredited interdisciplinary sleep programs in academic institutions

- An interdisciplinary approach requires the coordinated and integrated effort of not only the major medical fields involved in sleep clinical care (internal medicine and its relevant subspecialties, pediatrics neurology, psychiatry, psychology, and otolaryngology) but also other disciplines such as neuroscience, dentistry, nursing, and pharmacology.

\section{Adapted from Colten ${ }^{127}$}

Colten HR, Altevogt BM, editors. Institute of Medicine (US) Committee on Sleep Medicine and Research. Sleep Disorders and Sleep Deprivation: An Unmet Public Health Problem. Washington, DC: National Academies Press; 2006.

appropriate treatment should be a multidisciplinary approach. ${ }^{126}$

\section{DENTAL PROVIDERS' ROLE}

In 2006, the Institute of Medicine (currently known as the National Academy of Sciences) published its deep and probing report, "Sleep Disorders and Sleep Deprivation: An Unmet Public Health Problem". ${ }^{127}$ The key conclusions of this seminal report illuminated an opportunity for dentists to join the medical community for integrative care of children with sleep-related breathing disorders. The report specifically notes that there is high demand for the care of children with sleep-related breathing disorders, a great shortage of health care providers to provide diagnoses and treat these children, and recommends an interdisciplinary approach that includes dentistry in conjunction with myriad medical and healthcare domains ${ }^{127}$ (Table 3).

In providing collaborative patient-centered care, it is advisable for dentists to follow the established guidelines for the care of children with SDB, which have been promulgated by the American Academy of Pediatrics (AAP), American Academy of Pediatric Dentistry (AAPD), American Dental Association (ADA), and jointly by the American Academy of Sleep Medicine (AASM) and the American Academy of Dental Sleep Medicine (AADSM).

The AAP guidelines pertaining to dentists who treat children advise that "all children/adolescents should be screened for snoring" and referred to a qualified medical professional. Polysomnography should be performed in children/adolescents with snoring symptoms/signs of (POSA)," "weight loss is recommended in addition to other therapy in patients who are overweight or obese," and "intranasal corticosteroids are an option for children with mild (POSA) in whom AT is contraindicated or for mild postoperative (POSA)." 5

As part of the dentist's role with interprofessional collaboration, it is strongly recommended that dentists become knowledgeable to the same level as other members of the medical team and become intimately familiar with the AAP's algorithm for the diagnosis and management of POSA. ${ }^{128}$ The AAPD's recommendation for the timing of the first dental visit and the establishment of a dental home places the dentist in an important position to both screen and monitor their pediatric patients for signs and/or symptoms of SDB and POSA.

As previously mentioned, the most common etiology for children with POSA is adenotonsillar hypertrophy, therefore, during an oral examination the patient can be assessed for tonsillar hypertrophy as well as tongue position to rule out airway obstruction. ${ }^{103}$ The second most common etiology for POSA is obesity. Obesity is defined as a BMI exceeding the 95th percentile for age and sex based on standardized growth curves. ${ }^{129}$ The patient's BMI for age can be calculated from their height and weight, taken at the time of the dental examination as part of their overall growth and development assessment.

The AAPD guidelines serve as the preeminent standards for dentists treating children ${ }^{2}$ (Table 4). It is notable that the guidelines focus on the screening, clinical assessment, and then referral to medical specialists for workup and diagnosis. With further dental involvement in the patient's care, and based on the recommendation of the patient's physician, other treatment modalities may then be discussed. Thus, it is essential that dentists adhere to the AAPD guidelines when treating children and dentists who treat children conduct a thorough history and clinical screening for sleep-related breathing disorders. As recommended by the AAPD guidelines, the parents of pediatric patients should be asked if their children exhibit any symptoms of POSA ${ }^{2}$ (Table 5).

A positive response during a dental examination to a simple question such as, "Does your child snore or breathe through their mouth at night?" might serve as a segue to introduce a questionnaire to help identify additional signs and symptoms of POSA. If responses to the questionnaire 
Table 4: American Academy of Pediatric Dentistry (AAPD) Guidelines

\begin{tabular}{|l|l|}
\hline 1 & $\begin{array}{l}\text { Screen patients for snoring and sleep-related breathing } \\
\text { disorders }\end{array}$ \\
\hline 2 & Screen patient for OSA \\
\hline 3 & Assess the tonsillar pillar area for hypertrophy \\
\hline 4 & $\begin{array}{l}\text { Assess tongue positioning as it may contribute to obstruc- } \\
\text { tion }\end{array}$ \\
\hline 5 & Recognize obesity may contribute to OSA \\
\hline 6 & $\begin{array}{l}\text { Refer to an appropriate medical provider (e.g., otolaryn- } \\
\text { gologist, sleep medicine physician, pulmonologist) for di- } \\
\text { agnosis and treatment of any patient suspected of having } \\
\text { OSA }\end{array}$ \\
\hline 7 & $\begin{array}{l}\text { Consider non-surgical intraoral appliances only after a } \\
\text { complete orthodontic/craniofacial assessment of the pa- } \\
\text { tient's growth and development as part of a multidiscipli- } \\
\text { nary approach }\end{array}$ \\
\hline
\end{tabular}

Adapted from Pediatric Dentistry ${ }^{2}$

American Academy of Pediatric Dentistry. Policy on Obstructive Sleep Apnea. Pediatric Dentistry. 2017;38(special issue): 87-89.

\section{Copyright (C) 2017-18 by the American Academy of Pediatric Dentistry and reproduced with their per- mission.}

Table 5: Symptoms of Obstructive Sleep Apnea
\begin{tabular}{|l|l|}
\hline 1 & Excessive daytime sleepiness \\
\hline 2 & Loud snoring three or more nights per week \\
\hline 3 & $\begin{array}{l}\text { Episodes of breathing cessation witnessed by another } \\
\text { person }\end{array}$ \\
\hline 4 & Abrupt awakenings accompanied by shortness of breath \\
\hline 5 & Awakening with dry mouth or sore throat \\
\hline 6 & Morning headache \\
\hline 7 & Difficulty staying asleep \\
\hline 8 & Attention problems \\
\hline 9 & Mouth breathing \\
\hline 10 & Sweating \\
\hline 11 & Restlessness \\
\hline 12 & Waking up a lot \\
\hline
\end{tabular}

Adapted from Pediatric Dentistry ${ }^{2}$

American Academy of Pediatric Dentistry. Policy on Obstructive Sleep Apnea. Pediatric Dentistry. 2017;38(special issue): 87-89.

\section{Copyright (C) 2017-18 by the American Academy of Pediatric Dentistry and reproduced with their per- mission.}

indicate a likelihood of POSA, a timely referral to an appropriate medical provider for definitive diagnosis and treatment can be made. If a positive history for symptoms is reported, the dentist may consider the administration of a sleep questionnaire such as the Pediatric Sleep Questionnaire (PSQ). The PSQ (Figure S1) has been determined to be a valid and reliable instrument for the prediction of sleep-related breathing disorders for use in clinical research. ${ }^{130}$ In a retrospective longitudinal study by Chervin et al., the PSQ predicted OSA-related neurobehavioral morbidity "as well or better than polysomnography ". ${ }^{131}$

Per De Luca Canto et al., pairing the PSQ with a clinical examination improved the performance of the test, however, because it did not attain a high enough level of accuracy to replace the standard polysomnography, it should only be used as a screening tool to identify pediatric SDB. ${ }^{27}$ Therefore, dentists should consider incorporating the PSQ as part of their routine diagnostic examination criteria to screen pediatric patients for SDB because it may provide more useful information to the provider versus the clinical examination alone. After a child has been identified as having POSA, the periodic contact with the dental home can function as a mechanism to evaluate the ongoing efficacy of treatment. Long-term studies have shown that the positive effects of AT tend to diminish over time. Therefore, questions about snoring or other sleep-related signs and symptoms at the patient's periodic examinations might help illuminate cases where further intervention may be indicated. ${ }^{7}$

A thorough clinical oral examination will include the screening risks for SDB through the assessments of the tonsillar pillar area for hypertrophy and tongue positioning because it may contribute to obstruction. These assessments can be performed and rated with either the Mallampati classification system (actively protruding tongue) or the Friedman tongue classification (relaxed tongue), ${ }^{129,132}$ as shown in Figure 2, and are "significantly correlated with predicting OSA severity via a meta-analysis by Friedman et al". ${ }^{132}$

If the outcomes of the history, clinical examination, and PSQ are consistent with a possible diagnosis of SDB, it is critical that the findings be discussed with the child's adult caregiver(s) with an explanation of the potential medical risks of SDB. In alignment with interprofessional practice, the dentist can refer the child for a formal evaluation and diagnosis of SDB.

All dentists who treat children using oral conscious sedation (OCS) should be well versed in the risks involved if a patient has moderate-severe hypertrophy of the tonsils. One such risk is the increased likelihood for a patient to experience an upper airway obstruction during OCS. ${ }^{2}$ Litman et al. demonstrated that 14 of 25 children $(56 \%)$ with tonsillar hypertrophy who were about to undergo elective tonsillectomies experienced some degree of upper airway obstruction, whereas one patient experienced complete upper airway obstruction when premedicated with a combination of $50 \%$ nitrous oxide and oral midazolam $(0.5$ $\mathrm{mg} / \mathrm{kg}) .{ }^{133}$ This is significant considering that only 4 of 25 children $(16 \%)$ without a history of adenotonsillar hypertrophy showed partial airway obstruction after receiving the same sedative drugs prior to other medical surgical procedures. ${ }^{133}$ Because these are the same medications commonly used in OCS, this should educate medical and dental providers of the potential harm of performing OCS in these patients with tonsillar hypertrophy. ${ }^{133}$ Therefore, the Mallampati airway classification, Brodsky score, or Friedman 


\section{Figure 2: Mallampati (top) and Friedman Tongue Classification (bottom)}
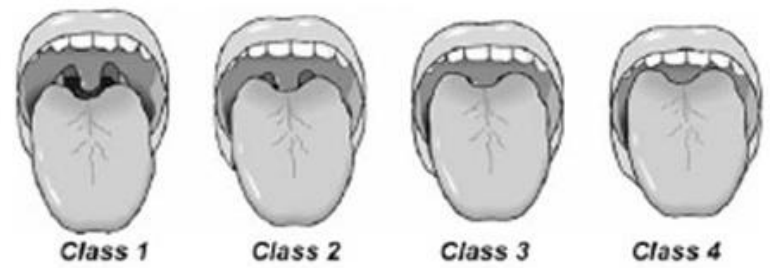

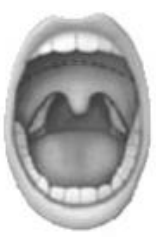

I

Entire uvula and tonsils are visible

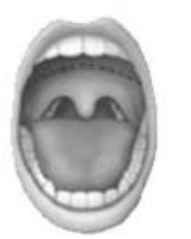

II

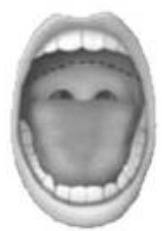

III

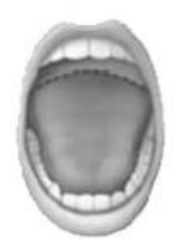

IV

Soft palate is visible, but Only hard palate

Entire uvula is visible, but tonsils are not visible uvula is not visible is visible

Adapted from Web ${ }^{129^{*}, 132^{* *}}$

*Mallampati (top) image approved for use by the American Academy of Sleep Medicine ${ }^{* *}$ Friedman (bottom) image modified and reprinted by permission of Sage Publications, Inc.

tongue classification are important tools in determining patients at risk because tonsillar hypertrophy that extends beyond $50 \%$ of the airway space may be more prone to potential airway obstruction. ${ }^{133}$

It is also important to take a thorough medical history including if the child snores (frequency, loudness), is obese, or whether POSA has been diagnosed, because these children are not ideal candidates for OCS. ${ }^{2}$ For children with obesity, the increased neck tissue along with limited mobility of the neck puts these children at higher risk for airway compromise. ${ }^{134}$ It should also be noted that patients with syndromes involving complex craniofacial features such as Treacher Collins syndrome, Pierre Robin sequence, Apert syndrome, Goldenhar syndrome, and Crouzon syndrome as well as patients who present with Down syndrome or mucopolysaccharidosis, are not appropriate patients for OCS because of the possibility of airway compromise and may be better suited for treatment under general anesthesia. ${ }^{134}$

As alluded to previously, the dentist should also be prepared to treat or refer the child for any OAT that may be recommended by the physician leading the care team for the child in whom SDB has been diagnosed. The management or referral for OAT may include a growth and development assessment; early treatment to develop adequate arch length, shape, position; and pharyngeal airway volume.

On October 23, 2017, the ADA-House of Delegates adopted the policy statement proposed by the ADA-Council on Dental Practice, which addressed dentistry's role in sleep-related breathing disorders, developed as a result of a 2015 resolution calling for the action. ${ }^{135}$ Therefore, it would be prudent for dentists to adhere to the current ADA policy $^{136}$ (Table S1). Current ADA policy outlines responsibilities for screening and referring patients, and they also specify the dentist's role in providing treatment with oral appliance therapy, as shown in yellow highlight in Table S1. ${ }^{136}$ The importance of continuing education related to the care of patients with SDB is a critical responsibility for dentists treating patients, and the relevant information is highlighted in green in Table S1. ${ }^{136}$

"The only dental practitioners currently considered qualified to treat OSA and fit mandibular advancement devices are Diplomates of the American Board of Dental Sleep Medicine or others who have undertaken comprehensive training in sleep medicine and/or sleep-related breathing disorders" which should be interpreted with caution because of the article's subjective opinions by the authors. ${ }^{137}$ Continuing education programs with an emphasis on pediatric sleep medicine are offered by various institutions such as the Brown University-Alpert Medical School, ${ }^{138}$ the American Academy of Dental Sleep Medicine, ${ }^{139}$ and the American Academy of Sleep Medicine. ${ }^{140}$ It is notable, however, that very few of the courses focus on the oral health care of children with sleep-related breathing disorders.

The University of Tennessee School of Dentistry is looking to educate fourth-year dental students with a course titled "Advanced TMD and Sleep Disordered Breathing" in order to pursue screening for OSA through 
already relevant guidelines created by the AASM, and eventually rotate their students through various clinical rotations in sleep medicine to gain exposure to polysomnography and treatment of OSA. ${ }^{137}$ As of 2003, only 18 of 43 reporting dental schools have introduced OSA into the school's curriculum according to a survey completed by Ivanhoe et al. ${ }^{141}$ Approximately 10 devices have been fabricated per year at the 7 schools that provide a student with a clinical encounter in the treatment of dental patients with OSA, confirming the fact that additional training is needed in dental schools to help treat this condition. ${ }^{141}$ Again, only qualified individuals who have pursued additional training in the topic of OSA should be treating these conditions in a multidisciplinary setting.

In children, dentists are often the first to probe for symptoms of POSA and can play an important role by noting the size of the tonsils when looking into a child's mouth. When symptoms are suggestive and/or tonsils are noted to be enlarged, the dentist can inform the child's parents and subsequently refer the patient for follow-up with their physician for a discussion of a proper diagnostic approach and possible treatment strategies. ${ }^{142}$ Dental schools lack consistent training at this time for SDB, OSA, and of particular concern, POSA, however, dentists can take the initiative to educate themselves with continuing education courses and can still screen and refer for signs and symptoms of POSA in their patients.

When the patient's primary chief complaint is primary snoring with no sleepiness, as stated in the guidelines: "the dentist must, before providing OAT, refer the patient to a sleep physician or family physician to review the patient's overall medical history and to exclude the presence of OSA". ${ }^{143}$ For those patients who do in fact experience daytime sleepiness with the possibility of OSA, "the dentist must refer the patient to a sleep medicine physician, who will be responsible for assessing the risk and severity of sleep apnea". ${ }^{143}$

\section{CONCLUSION}

Pediatric obstructive sleep apnea is highly prevalent in children and is associated with numerous health-related complications. Of equal concern is the likelihood that POSA will remain undiagnosed or diagnosis will be delayed in many children, given the paucity of available pediatric polysomnography laboratories. If POSA is left untreated, there are several potential harmful consequences, including attention or behavioral problems, reduced academic performance, cardiovascular disease, and growth / nutritional concerns ranging from failure to thrive or to obesity. ${ }^{1}$ Given the high prevalence of POSA in children, we advocate that all dentists become familiar with screening tools, diagnosis, and treatment of this disorder.

Based on this current literature review, we propose that the standard expectation of contemporary oral health care for children by dentists must include (1) education on the epidemiology, pathophysiology, and treatment considerations of children with POSA (POSA can be diagnosed only by physicians), (2) performing routine history, questionnaires, and clinical screening, and appropriate referrals to the medical members of the team, (3) becoming integrated with the medical team in addressing POSA, and (4) if so inclined, obtaining the appropriate higher education needed in fabricating and delivering oral appliances, only after a comprehensive orthodontic examination is completed for a well-rounded multidisciplinary approach. ${ }^{2}$ Accordingly, we suggest that all dental schools and postgraduate dental training programs incorporate training in the screening and management of children with POSA in their basic curriculum. Only the treating dentists who have obtained additional training in this area should be involved in this multidisciplinary role to avoid adverse outcomes in the treatment of POSA.

In addition, because POSA frequently affects children aged 2 to 7 years, and data are limited in regards to dental treatment approaches for this age group, there is a need for more meaningful clinical research to validate dental treatment strategies for this specific age population. Through careful collaboration with physician and healthcare colleagues, dentists can make significant contributions to the care of children with POSA while also becoming key contributors to the science of POSA, and thus, instilling a valuable effect on the quality of life and health of their pediatric patients.

The limitation of this review paper is in the selective bias of the individual cited literature. Varying degrees of evidence from expert opinion papers to meta-analysis studies have been presented for review. We have not provided a rating of evidence to each source; therefore, the strength of evidence for each topic needs to be taken into account by the reader.

\section{REFERENCES}

1. Chan J, Edman JC, Koltai PJ. Obstructive sleep apnea in children. Am Fam Physician. 2004;69(5):1147-1154.

2. American Academy of Pediatric Dentistry. Policy on Obstructive Sleep Apnea. Pediatr Dent. 2017;38(special issue):87-89.

3. Brunetti L, Rana S, Lospalluti ML, et al. Prevalence of obstructive sleep apnea syndrome in a cohort of 1,207 children of southern Italy. Chest. 2001;120(6):1930-1935.

4. Berry RB, Brooks R, Gamaldo CE, Harding SM, Marcus CL, Vaughn
BV. The AASM Manual for the Scoring of Sleep and Associated Events. Rules, Terminology and Technical Specifications, Darien, Illinois, American Academy of Sleep Medicine. 2012.

5. Marcus, CL, Brooks LJ, Ward SD, et al. Diagnosis and management of childhood obstructive sleep apnea syndrome. Pediatrics. 2012;130(3):714-755.

6. Haviv Y, Benoliel R, Bachar G, Michaeli E. On the edge between medicine and dentistry: Review of the dentist's role in the diagnosis 
and treatment of snoring and sleep apnea. Quintessence Int. 2014;45(4).

7. Guilleminault C, Sullivan SS. Towards restoration of continuous nasal breathing as the ultimate treatment goal in pediatric obstructive sleep apnea. Enliven: PediatrNeonatol Biol. 2014;1(1):001.

8. Halbower AC, Degaonkar M, Barker PB, et al. Childhood obstructive sleep apnea associates with neuropsychological deficits and neuronal brain injury. PLoS Med. 2006; 3(8):301.

9. McAuliffe P, Elaine P. Sleep apnoea for the dental practitioner. JrIr Dent Assoc. 2015;61(2):85-86, 88.

10. Bhattacharjee R, Kheirandish-Gozal L, Spruyt K, et al. Adenotonsillectomy outcomes in treatment of obstructive sleep apnea in children: a multicenter retrospective study. Am J RespirCrit Care Med. 2010;182(5):676-683.

11. Biggs SN, Walter LM, Jackman AR, et al. Long-term cognitive and behavioral outcomes following resolution of sleep disordered breathing in preschool children. PLoS One. 2015;10(9):e0139142.

12. Redline S, Tishler PV, Schluchter M, Aylor J, Clark K, Graham G. Risk factors for sleep-disordered breathing in children: associations with obesity, race, and respiratory problems. Am J RespirCrit Care Med. 1999;159(5):1527-1532.

13. Marcus CL. Sleep disordered breathing in children. Am J RespirCrit Care Med.2001;164(1):16-30.

14. Capua M, Ahmadi N, Shapiro C. Overview of obstructive sleep apnea in children: exploring the role of dentists in diagnosis and treatment. J Can Dent Assoc. 2009;75(4).

15. Ronen O, Malhotra A, Pillar G. Influence of gender and age on upperairway length during development. Pediatrics. 2007; 120(4):10281034.

16. Schellenberg JB, Maislin G, Schwab RJ. Physical findings and the risk for obstructive sleep apnea: the importance of oropharyngeal structures. Am J RespirCrit Care Med. 2000;162(2):740-748.

17. Gozal D. Sleep-disordered breathing and school performance in children. Pediatrics. 1998; 102(3):616-620.

18. Garetz SL, Mitchell RB, Parker PD, et al. Quality of life and obstructive sleep apnea symptoms after pediatric adenotonsillectomy. Pediatrics. 2015;135(2):e477-486.

19. Tauman R, Gozal D. Obesity and obstructive sleep apnea in children. PaediatrRespir Rev. 2006:7(4);247-259.

20. Verhulst SL, Schrauwen N, Haentjens D, et al. Sleep-disordered breathing in overweight and obese children and adolescents: prevalence, characteristics and the role of fat distribution. Arch Dis Child. 2007;92(3):205-208.

21. Lobstein T, Jackson-Leach R. Child overweight and obesity in the USA: prevalence rates according to IOTF definitions. PediatrObes. 2007;2(1):62-64.

22. White DP, Lombard RM, Cadieux RJ, Zwillich CW. Pharyngeal resistance in normal humans: influence of gender, age, and obesity. $J$ Appl Physiol. 1985;58(2):365-371.

23. Horner RL, Mohiaddin RH, Lowell DG, Shea SA, Burman ED, Longmore DB, Guz A. Sites and sizes of fat deposits around the pharynx in obese patients with obstructive sleep apnoea and weight matched controls. Eur Respir J. 1989;2(7):613-622.

24. Naimark A, Cherniack RM. Compliance of the respiratory system and its components in health and obesity. J Appl Physiol. 1960;15(3):377382.

25. Dayyat E, Kheirandish-Gozal L, Capdevila OS, Maarafeya MM, Gozal D. Obstructive sleep apnea in children: relative contributions of body mass index and adenotonsillar hypertrophy. Chest. 2009;136(1):137-144

26. Bhattacharjee R, Kim J, Kheirandish-Gozal L, Gozal D. Obesity and obstructive sleep apnea syndrome in children: a tale of inflammatory cascades. PediatrPulmonol. 2011;46(4):313-323.

27. De Luca Canto G, Singh V, Major MP, et al. Diagnostic capability of questionnaires and clinical examinations to assess sleep-disordered breathing in children: a systematic review and meta-analysis. $J \mathrm{Am}$ Dent Assoc. 2014;145(2):165-178.

28. Muzumdar H, Raanan A. Physiological effects of obstructive sleep apnea syndrome in childhood. RespirPhysiolNeurobiol. 2013;188(3):370-382.

29. Lewis KL. Apneas, hypoapneas and respiratory effort-related arousals: moving closer to a standard. CurrOpinPulm Med.2002;8(6):493497.

30. Dayyat E, Kheirandish-Gozal L, Gozal D. Childhood obstructive sleep apnea: one or two distinct disease entities? Sleep Med Clin. 2007;2(3):433-444.

31. Capdevila OS, Kheirandish-Gozal L, Dayyat E, Gozal D. Pediatric obstructive sleep apnea: complications, management, and long-term outcomes. Proc Am Thorac Soc. 2008;5(2):274-282.

32. Rosen D. Some infants with Down syndrome spontaneously outgrow their obstructive sleep apnea. ClinPediatr. 2010;49(11):1068-1071.

33. Waldman HB, Hasan FM, Perlman S. Down syndrome and sleep-disordered breathing: the dentist's role. $J$ Am Dent Assoc. 2009;140(3):307-312.

34. Huynh NT, Emami E, Helman JI, Chervin RD. Interactions between sleep disorders and oral diseases. Oral Dis. 2014;20(3):236-245.

35. Ahn YM. Treatment of obstructive sleep apnea in children. Korean J Pediatr. 2010;53(10):872-879.

36. Dixter C, Langlais RP, Lichty GC. Exercises in Dental Radiology, Volume 3, Pediatric Radiographic Interpretation. Philadelphia, PA. W.B. Saunders; 1980.

37. Rosen CL, Larkin EK, Kirchner HL, et al. Prevalence and risk factors for sleep-disordered breathing in 8- to 11-year-old children: association with race and prematurity. J Pediatr. 2003; 142:383-389.

38. Redline S, Tishler PV, Hans MG, Tosteson TD, Strohl KP, Spry K. Racial differences in sleep-disordered breathing in African-Americans and Caucasians. Am J RespirCrit Care Med. 1997;155(1):186192.

39. Buxbaum SG, Elston RC, Tishler PV, Redline S. Genetics of the apnea hypopnea index in Caucasians and African Americans: I. Segregation analysis. Genet Epidemiol. 2002;22(3):243-253.

40. Stepanski E, Zayyad A, Nigro C, Lopata M, Basner R. Sleep-disordered breathing in a predominantly African-American pediatric population. J Sleep Res. 1999 8(1):65-70.

41. Weinstock TG, Rosen CL, Marcus CL, et al. Predictors of obstructive sleep apnea severity in adenotonsillectomy candidates. Sleep. 2014;37(2):261-269.

42. Marcus CL, Moore RH, Rosen CL, et al. A randomized trial of adenotonsillectomy for childhood sleep apnea. $N$ Engl $J$ Med. 2013;368(25):2366-2376.

43. Amin R, Anthony L, Somers V, et al. Growth velocity predicts recurrence of sleep-disordered breathing 1 year after adenotonsillectomy. Am J RespirCrit Care Med. 2008;177(6):654-659.

44. Thongyam A, Marcus CL, Lockman JL, et al. Predictors of perioperative complications in higher risk children after adenotonsillectomy for obstructive sleep apnea: a prospective study. Otolaryngol Head Neck Surg. 2014;151(6):1046-1054.

45. Guilleminault C, Abad VC, Chiu HY, Peters B, Quo S. Missing teeth and pediatric obstructive sleep apnea. Sleep Breath. 2016;20(2):561568.

46. Larsen AJ, Rindal DB, Hatch JP, et al. Evidence supports no relationship between obstructive sleep apnea and premolar extraction: an electronic health records review. J Clin Sleep Med. 2015; 11(12):1443-1448.

47. GündüzArslan S, Devecioğlu Kama J, Ozer T, Yavuz I. Craniofacial and upper airway cephalometrics in hypohidrotic ectodermal dysplasia. DentomaxillofacRadiol. 2007;36(8):478-483.

48. Durán-Cantolla J, Alkhraisat MH, Martínez-Null C, Aguirre JJ, Guinea ER, Anitua E. Frequency of obstructive sleep apnea syndrome in dental patients with tooth wear. J Clin Sleep Med. 2015;11(4):445.

49. DiFrancesco RC, Junqueira PAS, Trezza PM, de Faria MEJ, Frizzarini R, Zerati FE. Improvement of bruxism after T \& A surgery. Int J PediatrOtorhinolaryngol. 2004;68(4):441-445.

50. Gregório PB, Athanazio RA, Bitencourt AGV, Neves FBCS, Terse R, Hora F. Symptoms of obstructive sleep apnea-hypopnea syndrome in children. JornalBrasileiro de Pneumologia. 2008;34(6):356-361.

51. Eftekharian A, Raad N, Gholami-Ghasri N. Bruxism and adenotonsillectomy. Int J PediatrOtorhinolaryngol. 2008;72(4):509-511.

52. Ohayon MM, Li KK, Guilleminault C. Risk factors for sleep bruxism in the general population. Chest. 2001;119(1):53-61.

53. Vendrame M, Kaleyias J, Valencia I, Legido A, Kothare SV. Polysomnographic findings in children with headaches. Pediatr Neurol. 2008;39(1):6-11.

54. Carra MC, Bruni O, Huynh N. Topical review: sleep bruxism, headaches, and sleep-disordered breathing in children and adolescents. $J$ Orofac Pain. 2012;26(4).

55. Simmons MS, Clark GT. The potentially harmful medical consequences of untreated sleep-disordered breathing: the evidence supporting brain damage. J Am Dent Assoc. 2009;140(5):536-542.

56. Montgomery-Downs HE, Crabtree VM, Capdevila OS, Gozal D. Infant-feeding methods and childhood sleep-disordered breathing. Pediatrics. 2007; 120(5):1030-1035.

57. Brew BK, Marks GB, Almqvist C, Cistulli PA, Webb K, Marshall 
NS. Breastfeeding and snoring: a birth cohort study. PloS One. 2014;9(1):e84956.

Sánchez-Molins M, Grau C.J, Lischeid GC, Ustrell TJ. Comparative study of the craniofacial growth depending on the type of lactation received. Eur J Paediatr Dent. 2010;11(2):87-92.

59. Diouf JS, Ngom PI, Badiane A, et al. Influence of the mode of nutritive and non-nutritive sucking on the dimensions of primary dental arches. IntOrthod. 2010;8(4):372-385.

60. Woolridge, MW. The 'anatomy' of infant sucking. Midwifery. 1986;2(4):164-171.

61. Peres KG, Cascaes AM, Nascimento GG, Victora CG. Effect of breastfeeding on malocclusions: a systematic review and meta-analysis. ActaPcediatr. 2015; 104(467):54-61.

62. Doğramacı EJ, Rossi-Fedele G, Dreyer CW. Malocclusions in young children: Does breast-feeding really reduce the risk? A systematic review and meta-analysis. J Am Dent Assoc. 2017;148(8):566-574.

63. Boronat-Catalá M, Montiel-Company JM, Bellot-Arcís C, AlmerichSilla JM, Catalá-Pizarro M. Association between duration of breastfeeding and malocclusions in primary and mixed dentition: a systematic review and meta-analysis. Sci Rep. 2017;7(1):5048.

64. Abreu LC, Paiva SM, Pordeus IA, Martins CC. Breastfeeding, bottle feeding and risk of malocclusion in mixed and permanent dentitions: a systematic review. Braz Oral Res. 2016; 30(1). Published Online March 28, 2016 (DOI: 10.1590/1807-3107BOR-2016.vol30.0022).

65. Frey L, Green S, Fabbie P, Hockenbury D, Foran M, Elder K. The essential role of the com in the management of sleep-disordered breathing: a literature review and discussion. Int J Orofacial Myology. 2014;40:42-55.

66. Gozal D, Kheirandish-Gozal L. Sleep apnea in children-treatment considerations. PaediatrRespir Rev. 2006;7(Suppl 1):S58-S61.

67. Cielo CM, Gungor A. Treatment options for pediatric obstructive sleep apnea. CurrProblPediatrAdolesc Health Care.2016;46(1):2733.

68. Bhattacharjee R, Kheirandish-Gozal L, Spruyt K, et al. Adenotonsillectomy outcomes in treatment of obstructive sleep apnea in children: a multicenter retrospective study. Am J RespirCrit Care Med. 2010;182(5):676-683.

69. Tauman R, Gulliver TE, Krishna J, et al. Persistence of obstructive sleep apnea syndrome in children after adenotonsillectomy. J Pediatr. 2006;149(6):803-808.

70. Mitchell RB. Adenotonsillectomy for obstructive sleep apnea in children: outcome evaluated by pre- and postoperative polysomnography. Laryngoscope. 2007;117(10):1844-1854.

71. Spencer DJ, Jones JE. Complications of adenotonsillectomy in patients younger than 3 years. Arch Otolaryngol Head Neck Surg. 2012;138(4):335-339.

72. Gallagher TQ, Wilcox L, McGuire E, Derkay CS. Analyzing factors associated with major complications after adenotonsillectomy in 4776 patients: comparing three tonsillectomy techniques. Otolaryngol Head Neck Surg. 2010;142(6):886-892.

73. De Luca Canto G, Pacheco-Pereira C, Aydinoz S, et al. Adenotonsillectomy complications: a meta-analysis. Pediatrics. 2015;136(4):702-718.

74. Mitchell RB, Kelly J. Adenotonsillectomy for obstructive sleep apnea in obese children. Otolaryngol Head Neck Surg. 2004;131(1):104108.

75. Arens R, Muzumdar H. Childhood obesity and obstructive sleep apnea syndrome. J Appl Physiol. 2010;108(2):436-444.

76. Holty JE, Guilleminault C. Maxillomandibular advancement for the treatment of obstructive sleep apnea: a systematic review and metaanalysis. Sleep Med Rev.2010;14(5):287-297.

77. Bacher M, Sautermeister J, Urschitz MS, Buchenau W, Arand J, Poets CF. An oral appliance with velar extension for treatment of obstructive sleep apnea in infants with Pierre Robin sequence. Cleft Palate Craniofac J. 2011;48(3):331-336.

78. Magliocca K, Helman JI. Distraction osteogenesis in the management of obstructive sleep apnea. In: Bell WH, Guerrero CA, eds. Distraction Osteogenesis of the Facial Skeleton. Hamilton, ON, Canada: B.C. Decker Inc. 2006: 431-436.

79. Won CH, Li KK, Guilleminault C. Surgical treatment of obstructive sleep apnea: upper airway and maxillomandibular surgery. Proc Am Thorac Soc. 2008;5(2):193-199.

80. Ashrafian H, Toma T, Rowland SP, et al. Bariatric surgery or nonsurgical weight loss for obstructive sleep apnoea? A systematic review and comparison of meta-analyses. Obes Surg. 2015;25(7):12391250.

81. Marcus CL, Rosen G, Ward SL, et al. Adherence to and effectiveness of positive airway pressure therapy in children with obstructive sleep apnea. Pediatrics. 2006;117(3): 442-451.

82. Uong EC, Epperson M, Bathon SA, Jeffe DB. Adherence to nasal positive airway pressure therapy among school-aged children and adolescents with obstructive sleep apnea syndrome. Pediatrics. 2007;120(5):1203-1211.

83. Downey R 3rd, Perkin RM, MacQuarrie J. Nasal continuous positive airway pressure use in children with obstructive sleep apnea younger than 2 years of age. Chest. 2000;117(6):1608-1612.

84. Hawkins SM, Jensen EL, Simon SL, Friedman NR. Correlates of pediatric CPAP adherence. J Clin Sleep Med. 2016;12(6):879-884.

85. Ramirez A, Khirani S, Aloui S, et al. Continuous positive airway pressure and noninvasive ventilation adherence in children. Sleep Med. 2013;14(12):1290-1294.

86. Koontz KL, Slifer KJ, Cataldo MD, Marcus CL. Improving pediatric compliance with positive airway pressure therapy: the impact of behavioral intervention. Sleep 2003;26(8):1010-1015.

87. Rains JC. Treatment of obstructive sleep apnea in pediatric patients. Behavioral intervention for compliance with nasal continuous positive airway pressure. ClinPediatr. 1995;34(10):535-541.

88. Prashad PS, Marcus CL, Maggs J, et al. Investigating reasons for CPAP adherence in adolescents: a qualitative approach. J Clin Sleep Med. 2013;9(12):1303-1313.

89. Ito S, Otake H, Tsuiki S, Miyao E, Noda A. Obstructive sleep apnea syndrome in a pubescent boy of short stature was improved with an orthodontic mandibular advancement oral appliance: a case report. $J$ Clin Sleep Med. 2015;11(1):75-76.

90. Kheirandish-Gozal L, Gozal D. Intranasal budesonide treatment for children with mild obstructive sleep apnea syndrome. Pediatrics. 2008;122(1):e149-55.

91. Kim J, Bhattacharjee R, Dayyat E, et al. Increased cellular proliferation and inflammatory cytokines in tonsils derived from children with obstructive sleep apnea. Pediatr Res. 2009;66(4):423-428.

92. Goldbart AV, Goldman JL, Li RC, Brittian KR, Tauman R, Gozal D. Differential expression of cysteinyl leukotriene receptors 1 and 2 in tonsils of children with obstructive sleep apnea syndrome or recurrent infection. Chest. 2004;126(1):13-18.

93. Kheirandish L, Goldbart AD, Gozal D. Intranasal steroids and oral leukotriene modifier therapy in residual sleep-disordered breathing after tonsillectomy and adenoidectomy in children. Pediatrics. 2006;117(1):e61-6.

94. Joosten SA, Hamilton GS, Naughton MT. Impact of weight loss management in OSA. Chest. 2017;152( 1):194-203.

95. Verhulst SL, Franckx H, Van Gaal L, De Backer W, Desager K. The effect of weight loss on sleep-disordered breathing in obese teenagers. Obesity. 2009;17(6):1178-1183.

96. De Luca Canto G, Pachêco-Pereira C, Aydinoz S, Major PW, FloresMir C, Gozal D. Biomarkers associated with obstructive sleep apnea and morbidities: a scoping review. Sleep Med. 2015;16(3):347-357.

97. De Luca Canto G, Pachêco-Pereira C, Aydinoz S, Major PW, FloresMir C, Gozal D. Biomarkers associated with obstructive sleep apnea: A scoping review. Sleep Med Rev. 2015;23:28-45.

98. Simmons MS. Dental sleep medicine-from snoring to sleep apnea. Dental Town. May 2010; 98-102.

99. Barsh LI. Responsibilities of the dental profession in the recognition and treatment of sleep breathing disorders. Sleep Breath. 1997;2(2):41-44.

100. Villa MP, Miano S, Rizzoli A. Mandibular advancement devices are an alternative and valid treatment for pediatric obstructive sleep apnea syndrome. Sleep Breath. 2011;16(4):971-976.

101. Cozza PR, Gatto FB, Prete L. Management of obstructive sleep apnoea in children with modified monobloc appliances. Eur J Paediatr Dent. 2004;5(1):24-29.

102. Camacho M, Chang ET, Song SA, et al. Rapid maxillary expansion for pediatric obstructive sleep apnea: A systematic review and metaanalysis. Laryngoscope. 2017;127(7):1712-1719.

103. Villa MP, Rizzoli A, Miano S, Malagola C. Efficacy of rapid maxillary expansion in children with obstructive sleep apnea syndrome: 36 months of follow-up. Sleep Breath.2011;15(2):179-184.

104. Timms DJ. Some medical aspects of rapid maxillary expansion. $B r J$ Orthod. 1974;1(4):127-132.

105. Schutz TC, Dominguez GC, Hallinan MP, Cunha TC, Tufik S. Class II correction improves nocturnal breathing in adolescents. Angle Orthod. 2011;81(2):222-228.

106. Guilleminault C, Monteyrol PJ, Huynh NT, Pirelli P, Quo S, Li K. Adeno-tonsillectomy and rapid maxillary distraction in pre-pubertal children, a pilot study. Sleep Breath. 2011;15(2):173-177. 
107. Eichenberger M, Baumgartner S. The impact of rapid palatal expansion on children's general health: a literature review. Eur J Paediatr Dent.2014;15(1):67-71.

108. Carvalho FR, Lentini-Oliveira DA, Prado LB, Prado GF, Carvalho LB. Oral appliances and functional orthopaedic appliances for obstructive sleep apnoea in children. Cochrane Database Syst Rev. 2016;10: CD005520.

109. Villa MP, Bernkopf E, Pagani J, Broia V, Montesano M, Ronchetti R. Randomized controlled study of an oral jaw-positioning appliance for the treatment of obstructive sleep apnea in children with malocclusion. Am J RespirCrit Care Med. 2002;165(1):123-127.

110. Machado-Júnior AJ, Zancanella E, Crespo AN. Rapid maxillary expansion and obstructive sleep apnea: A review and meta-analysis. Med Oral Patol Oral Cir Bucal. 2016; 21(4): e465-469.

111. Huynh NT, Desplats E, Almeida FR. Orthodontics treatments for managing obstructive sleep apnea syndrome in children: A systematic review and meta-analysis. Sleep Med Rev. 2016;25:84-94.

112. Barewal RM, Hagen CC. Management of snoring and obstructive sleep apnea with mandibular repositioning appliances. Dent Clin North Am. 2014;58(1):159-180.

113. Nazarali N, Altalibi M, Nazarali S, Major MP, Flores-Mir C, Major PW. Mandibular advancement appliances for the treatment of paediatric obstructive sleep apnea: a systematic review. Eur J Orthod. 2015;37(6):618-626.

114. Rogers RR. Past, present, and future use of oral appliance therapies in sleep-related breathing disorders. J Calif Dent Assoc.2012;40(2):151157.

115. Guilleminault C, Huang YS, Monteyrol PJ, Sato R, Quo S, Lin CH. Critical role of myofascial reeducation in pediatric sleep-disordered breathing. Sleep Med. 2013;14(6): 518-525.

116. Sakat MS, Sutbeyaz Y, Yuceler Z, Kantarci M, Kilic K, Kurt S. Cephalometric measurements with multislice computed tomography in patients with obstructive sleep apnea syndrome. J Craniofac Surg. 2016;27(1):82-86.

117. Flores-Mir C, Korayem M, Heo G, Witmans M, Miajor MP, Major PW. Craniofacial morphological characteristics in children with obstructive sleep apnea syndrome: a systematic review and meta-analysis. J Am Dent Assoc. 2013;144(3):269-277.

118. Patini R, Arrica M, Di Stasio E, Gallenzi P, Cordaro M. The use of magnetic resonance imaging in the evaluation of upper airway structures in paediatric obstructive sleep apnoea syndrome: a systematic review and meta-analysis. DentomaxillofacRadiol. 2016;45(7):20160136.

119. Major MP, Saltaji H, El-Hakim H, Witmans M, Major P, Flores-Mir C. The accuracy of diagnostic tests for adenoid hypertrophy: a systematic review. J Am Dent Assoc. 2014;145(3):247-254.

120. Cossellu G, Biagi R, Sarcina M, Mortellaro C, Farronato G. Threedimensional evaluation of upper airway in patients with obstructive sleep apnea syndrome during oral appliance therapy. J Craniofac Surg. 2015;26(3):745-748.

121. Simmons JH. Neurology of sleep and sleep-related breathing disorders and their relation to bruxism. J Calif Dent Assoc.2012;40(2):159167.

122. Carra MC, Bruni O, Huynh N. Topical review: sleep bruxism, headaches, and sleep-disordered breathing in children and adolescents. $J$ Orofac Pain. 2012;26(4):267-276.

123. De Luca Canto G, Singh V, Gozal D, Major PW, Flores-Mir C. Sleep bruxism and sleep-disordered breathing: a systematic review. J Oral Facial Pain Headache. 2014;28(4):299-305.

124. Sjoholm TT, Lowe AA, Miyamoto K, Fleetham JA, Ryan CF. Sleep bruxism in patients with sleep-disordered breathing. Arch Oral Biol. 2000;45(10):889-896.

125. Camacho M, Certal V, Abdullatif J, et al. Myofunctional therapy to treat obstructive sleep apnea: a systematic review and meta-analysis. Sleep. 2015;38(5):669-675.
126. Rogers Robert R. Dental sleep medicine: coming of age. Gen Dent. 2001;49(4):398-401.

127. Colten HR, Altevogt BM, eds. Institute of Medicine (US) Committee on Sleep Medicine and Research. Sleep Disorders and Sleep Deprivation: An Unmet Public Health Problem. Washington, DC: National Academies Press; 2006.

128. American Academy of Pediatrics. OSA Diagnosis and management flow chart. Available at "https://www.aap.org/en-us/_layouts/15/WopiFrame.aspx?sourcedoc=/en-us/Documents/OSA_Diagnosis Management Flow_Chart.pptx\&action=default". Accessed November 5, 2017.

129. Kumar HVM, Schroeder JW Jr, Gang Z, Sheldon SH.

Mallampati score and pediatric obstructive sleep apnea.J Clin Sleep Med 2014;10(9):985-990.

130. Chervin RD, Hedger K, Dillon JE, Pituch KJ. Pediatric sleep questionnaire (PSQ): validity and reliability of scales for sleep-disordered breathing, snoring, sleepiness, and behavioral problems. Sleep Med. 2000;1(1):21-32.

131. Chervin RD, Weatherly RA, Garetz SL et al. Pediatric Sleep Questionnaire Prediction of Sleep Apnea and Outcomes. Arch Otolaryngol Head Neck Surg. 2007;133(3):216-222.

132. Friedman M, Hamilton C, Samuelson C, Lundgren M, Pott T. Diagnostic value of the Friedman Tongue Position and Mallampati Classification for obstructive sleep apnea: a meta-analysis. Otolaryngol Head Neck Surg. 2013;148:540-547.

133. Litman RS1, Kottra JA, Berkowitz RJ, Ward DS. Upper airway obstruction during midazolam/nitrous oxide sedation in children with enlarged tonsils. Pediatr Dent. 1998;20(5):318-320.

134. Wage, NS, Baker S, Sedano HO. Pediatric conditions associated with compromised airway: part I--congenital. Pediatr Dent. 2009;31(3):236-248.

135. American Dental Association. ADA adopts policy on dentistry role in treating Obstructive Sleep Apnea, similar disorders. Available at "http://www.ada.org/en/press-room/news-releases/2017-archives/october/ada-adopts-policy-on-dentistry-role-in-treating-obstructivesleep-apnea". Accessed February 18, 2018.

136. American Dental Association. The role of dentistry in the treatment of sleep-related breathing disorders. Available at https://www.ada.org/en/ /media/ADA/Member\%20Center/FIles/The-Role-of-Dentistry-in-Sleep-Related-Breathing-Disorders. Accessed September 26. 2018.

137. Ivanoff CS., Hottel TL, Pancratz F. Is there a place for teaching obstructive sleep apnea and snoring in the predoctoral dental curriculum.J Dent Educ. 2012;76(12):1639-1645.

138. Brown University-Alpert Medical School. Ninth Biennial Conference on Pediatric Sleep Medicine. Available at "https://www.brown.edu/academics/medical/education/other-programs/continuing-medical-education/pedsleepmedconference". Accessed November 5, 2017.

139. American Academy of Dental Sleep Medicine. AADSM education. Available at "http://www.aadsm.org/Education.php". Accessed July 2, 2018

140. American Academy of Sleep Medicine. Continued medical education. Available at: "https://aasm.org/professional-development/cme/". Accessed November 5, 2017.

141. Ivanhoe JR., Frazier KB, Parr GR, Haywood VB. The teaching and treatment of upper airway sleep disorders in North American dental schools. J Prosthet Dent. 2003;89(3):292-296.

142. Padmanabhan V, Kavitha PR, Hegde A. Sleep disordered breathing in children-a review and the role of a pediatric dentist. J ClinPediatr Dent. 2010;35(1):15-21.

143 Gauthier L, Almeida F, Arcache P, et al. Position paper by Canadian dental sleep medicine professionals regarding the role of different health care professionals in managing obstructive sleep apnea and snoring with oral appliances. Can Respir J. 2012;19(5):307-309 


\section{SUBMISSION \& CORRESPOND- ENCE INFORMATION}

Submitted for publication November 7, 2017

Submitted in final revised form March 1, 2018

Accepted for publication June 1, 2018

Address correspondence to: Jacy Stauffer, DMD; San Diego Children's Dental Clinic / San Ysidro Health, 8110 Birmingham Way, Building 28, San Diego, CA 92123, Email: jacy.stauffer@ syhealth.org

\section{DISCLOSURE STATEMENT}

There are no declarations to be made in regard to financial support, off-label/investigational use. The authors have no conflicts of interest to disclose. This manuscript does not report on a clinical trial. 


\section{SUPPLEMENTAL MATERIALS}

\begin{tabular}{|c|c|c|}
\hline & YES & No \\
\hline \multicolumn{3}{|l|}{ While sleeping, does your child... } \\
\hline snore more than half the time? & $\square$ & $\square$ \\
\hline always snore? & $\square$ & $\square$ \\
\hline snore loudly? & $\square$ & $\square$ \\
\hline have "heavy" or loud breathing? & $\square$ & $\square$ \\
\hline have trouble breathing, or struggle to breathe? & $\square$ & $\square$ \\
\hline \multicolumn{3}{|l|}{ Have you ever... } \\
\hline seen your child stop breathing during the night? & $\square$ & $\square$ \\
\hline \multicolumn{3}{|l|}{ Does your child... } \\
\hline tend to breathe through the mouth during the day? & $\square$ & $\square$ \\
\hline have a dry mouth on waking up in the morning? & $\square$ & $\square$ \\
\hline occasionally wet the bed? & $\square$ & $\square$ \\
\hline \multicolumn{3}{|l|}{ Does your child.... } \\
\hline wake up feeling unrefreshed in the morning? & $\square$ & $\square$ \\
\hline have a problem with sleepiness during the day? & $\square$ & $\square$ \\
\hline Has a teacher or other supervisor commented that your child appears sleepy during the day? & $\square$ & $\square$ \\
\hline Is it hard to wake your child up in the morning? & $\square$ & $\square$ \\
\hline Does your child wake up with headaches in the morning? & $\square$ & $\square$ \\
\hline Did your child stop growing at a normal rate at any time since birth? & $\square$ & $\square$ \\
\hline Is your child overweight? & $\square$ & $\square$ \\
\hline \multicolumn{3}{|l|}{ This child often... } \\
\hline does not seem to listen when spoken to directly? & $\square$ & $\square$ \\
\hline has difficulty organizing task and activities? & $\square$ & $\square$ \\
\hline is easily distracted by extraneous stimuli? & $\square$ & $\square$ \\
\hline fidgets with hands or feet or squirms in seat? & $\square$ & $\square$ \\
\hline is 'on the go' or often acts as if 'driven by a motor'? & $\square$ & $\square$ \\
\hline interrupts or intrudes on others (e.g. butts into conversations or games)? & $\square$ & $\square$ \\
\hline Total number of "Yes" responses & & \\
\hline More than 8 positive responses may indicate a problem with sleep related breath & rder & \\
\hline
\end{tabular}

Copyright 2007 The Regents of University of the University of Michigan 
Table S1: American Dental Association Policy, Dentistry's Role in Sleep Related Breathing Disorders

\begin{tabular}{l|l}
\hline 1 & Dentists are encouraged to screen patients for SRBD as part of a comprehensive medical and dental
\end{tabular} history to recognize symptoms such as daytime sleepiness, choking, snoring or witnessed apneas and an evaluation for risk factors such as obesity, retrognathia, or hypertension. If risk for SRBD is determined, these patients should be referred, as needed, to the appropriate physicians for proper diagnosis.

2 In children, screening through history and clinical examination may identify signs and symptoms of deficient growth and development, or other risk factors that may lead to airway issues. If risk for SRBD is determined, intervention through medical/dental referral or evidenced based treatment may be appropriate to help treat the SRBD and/or develop an optimal physiologic airway and breathing pattern.

3 Oral appliance therapy is an appropriate treatment for mild and moderate sleep apnea, and for severe sleep apnea when a CPAP is not tolerated by the patient.

$4 \quad$ When oral appliance therapy is prescribed by a physician through written or electronic order for an adult patient with obstructive sleep apnea, a dentist should evaluate the patient for the appropriateness of fabricating a suitable oral appliance. If deemed appropriate, a dentist should fabricate an oral appliance.

$5 \quad$ Dentists should obtain appropriate patient consent for treatment that reviews the proposed treatment plan, all available options and any potential side effects of using OAT and expected appliance longevity.

6 Dentists treating SRBD with OAT should be capable of recognizing and managing the potential side effects through treatment or proper referral.

7 Dentists who provide OAT to patients should monitor and adjust the Oral Appliance $(\mathrm{OA})$ for treatment efficacy as needed, or at least annually. As titration of OAs has been shown to affect the final treatment outcome and overall OA success, the use of unattended cardiorespiratory (Type 3 ) or (Type 4) portable monitors may be used by the dentist to help define the optimal target position of the mandible. A dentist trained in the use of these portable monitoring devices may assess the objective interim results for the purposes of OA titration.

8 Surgical procedures may be considered as a secondary treatment for OSA when CPAP or OAT is inadequate or not tolerated. In selected cases, such as patients with concomitant dentofacial deformities, surgical intervention may be considered as a primary treatment.

$9 \quad$ Dentists treating SRBD should continually update their knowledge and training of dental sleep medicine with related continuing education.

10 Dentists should maintain regular communications with the patient's referring physician and other healthcare providers to the patient's treatment progress and any recommended follow-up treatment.

11 Follow-up sleep testing by a physician should be conducted to evaluate the improvement or confirm treatment efficacy for the OSA, especially if the patient develops recurring OSA relevant symptoms or comorbidities.

Copyright $\odot 2018$ American Dental Association. All rights reserved. Reprinted by permission. https://www.ada.org/en/ /media/ADA/Member\%20Center/Flles/The-Role-of-Dentistry-in-Sleep-Related-Breathing-Disorders $^{136}$ 